\title{
Distributive Numerals and Distance Distributivity in Tlingit (and Beyond)
}

\author{
Seth Cable \\ University of Massachusetts Amherst \\ June 12, 2013
}

\section{Abstract and Keywords}

This paper develops a formal semantic and syntactic analysis of distributive numerals in Tlingit, a highly endangered language of Alaska, British Columbia and the Yukon. Such numerals enforce a 'distributive reading' of the sentence, and thus are one instance of the broader phenomenon of 'distance distributivity' (Zimmermann 2002). As in many other languages, a Tlingit sentence containing a distributive numeral can describe two distinct kinds of 'distributive scenarios': (i) a scenario where the distribution is over some plural entity ( $c f$. 'My sons caught three fish each'), and (ii) one where the distribution is over some plural event ( $c f$. 'My sons caught three fish each time') (Gil 1982, Choe 1987, Zimmermann 2002, Oh 2005). Despite this apparent ambiguity, I put forth a univocal semantics for Tlingit distributive numerals, one whereby they consistently invoke quantification over events. Under this semantics, the ability for distributive numerals to describe both kinds of scenarios in (i) and (ii) is not due to an ambiguity, but instead to the sentences having relatively weak truth-conditions. In contrast to prior analyses of distributive numerals and distance distributivity, the proposed semantics does not actually make use of distributive operators, but nevertheless retains a rather conservative picture of the syntax-semantics interface. The analysis can also account for certain locality effects noted for distance distributives in Korean and German (Zimmermann 2002, Oh 2005), as well as an intriguing puzzle regarding distributive numerals and pluractionality in Kaqchikel (Henderson 2011). Finally, I show how the analysis can be extended to the well-known case of English 'binominal each'.

Keywords:

distributivity, distributive numeral, distance distributivity, anti-quantifier, dependent indefinite, pluractional, pluractional adverb, binominal each, Tlingit 


\section{Distributive Numerals and Distance Distributivity in Tlingit (and Beyond) ${ }^{1}$}

\section{Distributive Numerals, Their Analytic Challenges, and Prior Approaches}

As first noted by Gil (1982), distributive numerals pose many difficult challenges to theories of the syntax-semantics interface. In this paper, I present and defend a novel analysis of these constructions, one that offers important conceptual advantages over previous accounts. A second, parallel goal of this paper is to document and analyze the distributive numeral construction of Tlingit, a highly endangered and understudied Na-Dene language of Alaska, British Columbia and the Yukon (Boas 1917, Naish 1966, Story 1966, Leer 1991, Dauenhauer \& Dauenhauer 2000, Cable 2010). Although Tlingit provides the primary empirical content of the paper, I also show how the proposed account offers improved insight into various puzzles concerning distributive numerals in other languages.

The term 'distributive numeral' has its roots in classical grammatical and philological studies, but was introduced into formal linguistics through the work of Gil (1982). Since Gil's seminal work, this phenomenon has been given several other technical designations, including 'Anti-Quantifier' (Choe 1987), 'Dependent Indefinite' (Farkas 1997), and 'Distance Distributivity' (Zimmermann 2002). ${ }^{2}$ Indeed, the last of these - 'Distance Distributivity' - is often taken to be a broader concept, one that also encompasses so-called 'binominal each' in English, a construction that is not universally recognized as a type of distributive numeral (Gil 1982). As we will see, the analysis developed here for distributive numerals in Tlingit offers new insights into the broader category of distance distributivity as well.

Whatever the label, the phenomenon of key interest is the one roughly defined below.

1 Deepest thanks are owed first and foremost to Tlingit elders Beatrice Brown (Sa.áaxw), Margaret Dutson (Chiksháani), Selena Everson (Kaséix ), William Fawcett (Kóoshdaakwwísh), and Helen Sarabia (ㅁáachku.aakww). I am deeply grateful for all that they have taught me regarding the Tlingit language, as well as for their generosity, patience, and good humor. I would also like to dedicate this work to the memory of Beatrice Brown (Sa.áaxw). I was extremely fortunate to have gotten the chance to meet and learn from her during the summer of 2011 . This project owes an immeasurable amount both to the depth of her knowledge and to the warmth and kind spirit that she brought to all of our meetings.

I would also like to thank all those who have commented upon earlier versions of this work: Elizabeth Bogal-Allbritten, Greg Carlson, Lucas Champollion, James Crippen (Dzéiwsh), Aniko Csirmaz, Henry Davis, Hamida Demirdache, Mitcho Erlewine, Bob Frank, Lyn Frazier, Robert Henderson, Chisato Kitagawa, Angelika Kratzer, Nick Lacara, Suzi Lima, Jim McCloskey, Yangsook Park, Tom Roeper, Mats Rooth, Roger Schwarzschild, Peggy Speas, Yasu Sudo, Anna Szabolcsi, and Judith Tonhauser, as well as two anonymous reviewers for Language. In addition, I'd like to thank audiences at SULA 7 (Cornell University), NELS 43 (CUNY), Yale University, and the University of Utah.

I owe many thanks to Alice Taff, for her crucial logistical support of this study. Finally, warmest thanks to

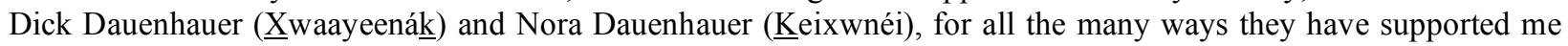
and my studies. This research was made possible through a grant from the Jacobs Research Funds.

${ }^{2}$ It should be noted that each of these four terms is associated with particular, distinct analyses of the construction in question, and so therefore comes with its own peculiar theoretical baggage. For example, the term 'dependent indefinite' is typically used in work making use of the core ideas of Dynamic Plural Logic (Farkas 1997, Henderson 2011). However, each of these labels generally picks out the same empirical phenomena, and so they can be treated as functional synonyms. Such synonymy is not uncommon in literature focusing on specific constructions, e.g. the labels 'pluractional' (Newman 1990, Lasersohn 1995) vs. 'frequentative' (van Geenhoven 2004) vs. 'verbal plurality' (Cusic 1981) vs. 'distributive' (Barker 1964). 


\section{Distributive Numeral}

A morphosyntactic construction containing a numeral, whereby (i) the sentence as a whole receives a distributive reading, and (ii) under the allowable readings, the numeral contained within the construction must be interpreted as if it is within the scope of a distributive operator. ${ }^{3}$

To help clarify this definition, the 'distributive operator' mentioned in (1) is essentially the following (Lasersohn 1995, Schwarzschild 1996).

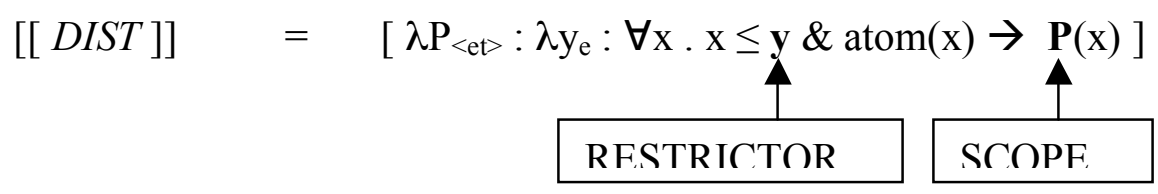

Represented here as ' $D I S T$ ', this operator denotes a function that takes as argument a property ' $\mathrm{P}$ ' and a plurality ' $\mathrm{y}$ ', and returns a value of True if and only if every individual $\mathrm{x}$ within the plurality $\mathrm{y}$ has property $\mathrm{P}$. Thus, this operator serves to 'distribute' the property $\mathrm{P}$ over the entities making up the plurality y. As indicated in (2), the 'scope' of this operator is simply the property $\mathrm{P}$ that is distributed over $\mathrm{y}$, while the plurality $\mathrm{y}$ is commonly referred to as the 'restrictor' of the operator.

With this background in place, let us observe how the definition in (1) is exemplified via the following Tlingit sentences.

\section{Plain Numerals and Distributive Numerals in Tlingit ${ }^{4}$}
a. Nás'k xáat has aawasháat.
three fish 3plS.3O.caught
'They caught three fish.'

\footnotetext{
3 Please note the italicized 'as if' in this definition, and that condition (ii) does not state that the numeral must actually be interpreted within the scope of a distributive operator. Condition (ii) here instead merely states that the meaning is one that could (perhaps imperfectly) be represented by a formula where the numeral scopes under such an operator. Thus, the definition in (1) does not actually commit one to using distributive operators such as (2) in the analysis of distributive numerals. This is crucial, as one advantage of the analysis I propose here is that it makes no use of such operators.

${ }^{4}$ In this paper, I use the following abbreviations in the glossing of example sentences: $1 \mathrm{sgS}$ 'first person singular subject', $2 \mathrm{sgS}$ 'second person singular subject', $3 \mathrm{O}$ 'third person object', 3plS 'third person plural subject', 3sgS 'third person singular subject', ACC 'accusative case', CL 'classifier', DIST 'distributive numeral marker', ERG '(optional) ergative case', FOC 'focus particle', NOM 'nominative case', PA 'pluractional suffix', Q 'question particle'.

${ }^{5}$ Throughout this paper, I indicate whether a Tlingit sentence structure was (i) constructed by the author and judged by speakers to be well-formed, or (ii) actually spontaneously spoken by the language consultants themselves. In the former case, the Tlingit sentence will be followed by a '(C)', for 'constructed'. In the latter case, I will provide the initials of the language consultant(s) who provided the sentence in question: (BB) for Beatrice Brown, (MD) for Margaret Dutson, (SE) for Selena Everson, (WF) for William Fawcett, and (HS) for Helen Sarabia. Again, it should be noted that all sentences marked with a '(C)' were judged by all the consultants to be well-formed.

${ }^{6}$ I will in this paper provide only the roughest of glosses for individual Tlingit words, which can be morphologically quite complex. This simplification is the most radical for verbs, as I provide glosses only for their lexical content and their agreement morphology, leaving out all their rich aspect and mood inflectional content.
} 
$\begin{array}{llll}\text { b. Nás'gigáa } & \text { xáat has aawasháat. } \\ \text { three.DIST fish } & \text { 3plS.3O.caught }\end{array}$

(BB), (WF)

'They caught three fish each.' Or, 'They caught three fish each time.'

Sentence (3a) contains the unmarked numeral nás'k 'three'. As detailed in Section 3, this sentence can, like its English translation, receive both so-called 'collective' and 'cumulative' readings (where exactly three fish are caught), and generally resists a 'distributive' reading (where the number of fish caught is a multiple of three). Sentence (3b), however, contains the distributive numeral nás'gigáa 'three.DIST'. This sentence cannot receive either the collective or cumulative reading of (3a), and only permits a distributive interpretation. Furthermore, as suggested by the two translations under (3b), such sentences appear at first glance to be ambiguous, in that they can describe two very different kinds of 'distributive scenarios'. These two scenario types are sketched in more detail below.

a. Participant-Distributive Scenario: Each of them caught three fish.

$$
\begin{array}{rc}
\forall \mathrm{x} . \mathrm{x} \leq \text { 'they' \& atom(x) } & \rightarrow \quad \exists \text { e. } \exists \mathrm{y} . \text { three.fish }(\mathrm{y}) \& \mathrm{x} \text { caught } \mathrm{y} \text { in e } \\
\text { Restrictor of 'DIST' } & \text { Scope of 'DIST' }
\end{array}
$$

b. Event-Distributive Scenario: They caught fish three at a time.

$$
\begin{gathered}
\exists \text { e. } \forall \mathrm{e}^{\prime} . \mathrm{e} \text { ' } \leq \mathbf{e} \& \text { atom(e') } \\
\text { Restrictor of 'DIST' }
\end{gathered} \rightarrow \begin{gathered}
\exists \text {. three.fish }(\mathrm{y}) \& \text { 'they' caught y in e' } \\
\text { Scope of 'DIST' }
\end{gathered}
$$

In the scenario described in (4a), for each individual member $x$ of some contextually salient plurality 'they', there is an event e of $\mathrm{x}$ catching three fish. Throughout this paper, I will refer to such scenarios as 'participant-distributive' scenarios, given that the distribution of 'three fish' appears to be over some plural participant in the described scenario. In scenario (4b), however, there is a plurality of events e, and each individual member e' of e is an event of 'they' catching three fish (altogether). Given that there are three fish to each event of catching (but not necessarily to each fisherman), I will refer to scenarios like (4b) as 'event-distributive' scenarios.

As we will see in more detail below, Tlingit sentences like (3b) are true both in participant-distributive scenarios like (4a) and event-distributive scenarios like (4b). Furthermore, as the logical formulae in (4) make clear, if we attempt to characterize the scenarios in $(4 a, b)$ using a distributive operator like that in (2), then in both (4a) and (4b) the denotation of 'three fish' lies within the scope of that operator. Consequently, we find that the Tlingit construction in (3b) fits the general definition in (1) of a 'distributive numeral'.

When presented in these terms, distributive numerals raise two key challenges for theories of the syntax-semantics interface. The first simply concerns the ability for sentences containing such numerals to describe both participant-distributive and event-distributive scenarios. After all, these kinds of scenarios seem to be quite distinct, and so it is a non-trivial task to develop a semantics for distributive numerals that can apply to both. In particular, note that while the restrictor of DIST in (4a) is a plurality of entities, the restrictor in (4b) is a plurality of events. Given that entities and events are commonly assumed to be two distinct semantic types $-e$ and $\varepsilon$, respectively - one actually cannot (under common assumptions) obtain the meaning in (4b) from the basic distributive operator in (2). For this reason, providing a single, unified 
semantics that allows for distribution over both entities and events is a key challenge for any analysis of distributive numerals.

However, an even greater, more fundamental challenge is simply explaining how the distributive numeral is able to enforce the distributive reading of the sentence (Zimmermann 2002). After all, as the formulae in (4) make clear, the distributive numeral in sentences like (3b) does not directly combine syntactically with either the scope or the restrictor of a distributive operator like (2). Rather, the numeral within the construction appears to contribute a strict subpart of the scope of such an operator. Consequently, while the distributive numeral appears to somehow contribute the meaning of (2), its (surface) syntactic position is not one from which meanings akin to $(4 \mathrm{a}, \mathrm{b})$ could be derived via such an operator. Put more simply and broadly, the distributive numeral morphology (e.g. the suffix -gáa in (3b)) does not itself directly mark either the distributed property or the plurality distributed over. Rather, it marks only a strict subpart of the distributed property. It appears, then, that this morphology somehow signals the distribution of a property larger than the constituent it marks, and so there is an apparent mismatch between the surface location of this morphology (the numeral) and the locus of its semantic effect (the larger, distributed property). As we will see presently, capturing and explaining this apparent mismatch is an especially difficult challenge.

In response to these challenges, prior approaches to distributive numerals have introduced mechanisms that in various ways diverge from common assumptions concerning the syntaxsemantics interface. For reasons of space, I'll consider just three general approaches that have emerged in the last decade.

The first such approach is that of Oh $(2001,2005)$, who focuses upon the distributive numerals of Korean (Section 6). Under this approach, distributive numerals don't actually themselves contribute distributivity to the meaning of the sentence. Rather, distributive numerals are semantically identical to unmarked numerals. They are, however, subject to a special, syntactic licensing condition, requiring them to be c-commanded at LF by the distributive operator in (2). Consequently, sentences like (3b) are only able to receive the LFs in $(5 a, b)$.

The Possible LF Structures for Sentence (3b), in the Analysis of Oh $(2001,2005)$

a. Syntax: $\quad\left[\operatorname{pro}\left[\underline{\boldsymbol{D I S T}}\left[\exists \mathrm{E}\left[\mathrm{e}\left[\begin{array}{lll}{[\text { nás'gigáa }} & \text { xáat }] & \text { has aawasháat } \\ \text { three.DIST } & \text { fish } & \text { 3plS.3O.caught }\end{array}\right]\right.\right.\right.\right.$

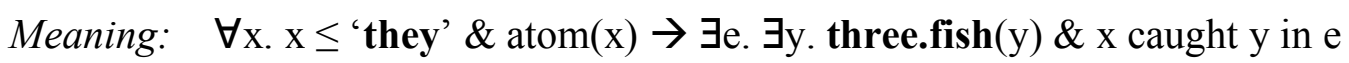

b. Syntax: $\quad[\exists \mathrm{e}[\mathrm{e}[\underline{\boldsymbol{D I S T}}[$ pro $[$ [ nás'gigáa xáat ] has aawasháat ] $\ldots$ ] three.DIST fish 3plS.3O.caught

Meaning: $\exists$ e. $\forall$ e'. e' $\leq \mathbf{e} \&$ atom(e') $\rightarrow \exists y$. three.fish(y) \& 'they' caught y in e'

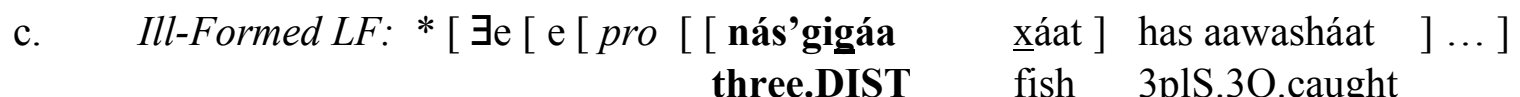

Meaning: $\exists$ e. $\exists y$. three.fish(y) \& $\mathrm{x}$ caught $\mathrm{y}$ in e (collective/cumulative reading) 
The ill-formedness of LF (5c) entails that sentences containing distributive numerals will only allow distributive readings, and won't allow either collective or cumulative ones. Furthermore, Oh's system maps the LF in (5a) to the participant-distributive interpretation, while the LF in (5b) is mapped to the event-distributive interpretation. In this way, Oh $(2001,2005)$ predicts exactly the range of interpretations that sentences like (3b) are observed to have.

Although Oh's $(2001,2005)$ account is in many ways quite elegant, it does present a more complicated picture of the syntax-semantics interface, in several respects. First and foremost is the introduction of the sui generis 'licensing mechanism' holding between DIST and distributive numerals. The nature of this mechanism is left rather unclear in Oh's work, and although it is often analogized to the licensing of NPIs, it appears to be subject to locality conditions that NPI licensing is not (Section 6; Oh 2001, fn. 17). Moreover, for reasons discussed above, in order to derive both the participant- and event-distributive interpretations, Oh $(2001,2005)$ must assume two distinct DIST operators, one taking entities as restrictors and the other taking events. The existence of these two, semantically distinct DIST operators renders a principled account of the crucial licensing mechanism all the more difficult. Finally, for more complex examples (e.g. (33)-(35), below), several additional covert movement operations must be posited, which in the case of Korean appear contrary to the language's more general preference for surface scope (Beck \& Kim 1997, Beck 2006).

A second general approach to distributive numerals is represented in the work of Zimmermann (2002) and Champollion (2012). Although Champollion's (2012) analysis is in many respects different from Zimmermann's, it shares certain key features and so is subject to similar criticisms (Footnote 7). For reasons of space, my discussion here will center on the analysis developed by Zimmermann (2002).

Unlike Oh (2001, 2005), Zimmermann and Champollion propose that distributive numerals do (at some level) directly contribute a distributive operator akin to (2). Under Zimmermann's account, an NP modified by a distributive numeral has the syntax in (6).

$$
\text { [ D [ [ three fish ] [ } \operatorname{Pred}_{\mathrm{i}}[\text { DIST pro } \mathrm{k}] \ldots \text { ] }
$$

According to this syntax, a distributive numeral construction contains four main ingredients: (i) the distributive operator DIST, (ii) an indexed variable rro $_{\mathrm{k}}$, (iii), a special indexed element $\operatorname{Pred}_{i}$, (iv) a determiner $D$. These elements play the following semantic roles in the construction: (i) DIST contributes distributivity, (ii) pro $_{\mathrm{k}}$ provides the restrictor of DIST, (iii) the indexed element Pred $_{i}$ combines with 'three fish' and $D$ to yield the property distributed over pro $_{\mathrm{k}}$. Zimmermann provides a formal semantics for each of these elements, which together map the structure in (6) to the denotation in (7).

$$
\begin{aligned}
& \forall \mathrm{x} . \mathrm{x} \leq \boldsymbol{k} \& \text { atom }(\mathrm{x}) \rightarrow \exists \mathrm{y} \text {. three.fish }(\mathrm{y}) \& \boldsymbol{i}(\mathrm{y})(\mathrm{x}) \\
& \text { 'For all individuals } \mathrm{x} \text { in } \boldsymbol{k} \text {, there are three fish } \mathrm{y} \text { such that relation } \boldsymbol{i} \text { holds of } \mathrm{x} \text { and } \mathrm{y} \text { ' }
\end{aligned}
$$

Note that in the denotation above, there are two (boldfaced) free variables, $k$ and $i$. Via special mechanisms introduced by Zimmermann, these variables can be bound by other elements within the clause. For example, if the variable $k$ is bound by the plural subject in (3b), a participantdistributive interpretation can be obtained (8a). For the event-distributive interpretation of (3b), Zimmermann proposes that the variable $k$ is left free, and is simply understood in context to refer to a salient plurality of events (8b). 
a. $\quad$ Participant-Distributive Interpretation

$\forall \mathrm{x} . \mathrm{x} \leq$ 'they' \& atom( $\mathrm{x}) \rightarrow \exists \mathrm{y}$. three.fish $(\mathrm{y}) \& \exists \mathbf{e}$. $\mathrm{x}$ caught $\mathrm{y}$ in $\mathbf{e}$

'For all individuals $\mathrm{x}$ in 'they' there are three fish $\mathrm{y}$ such that $\mathrm{x}$ caught $\mathrm{y}$ '

b. Event-Distributive Interpretation

$\forall \mathrm{x} . \mathrm{x} \leq \mathbf{e} \&$ atom(x) $\rightarrow \exists \mathrm{y}$. three.fish(y) \& 'they' caught $\mathbf{y}$ in $\mathbf{x}$

'For all individuals (events) $\mathrm{x}$ in $\mathbf{e}$, there are three fish $\mathrm{y}$ such that 'they' caught $\mathrm{y}$ in $\mathrm{x}$ '

Although Zimmermann's account avoids the problems inherent in the syntactic licensing condition of Oh $(2001,2005)$, it introduces its own complications to the theory of the syntaxsemantics interface. Most notably, in order to derive the sentence-meanings in (8) from the semantics in (7), a whole host of special composition rules must be introduced. The reader is referred to Zimmermann (2002) for details, but these special rules largely center upon the binding of the variable $i$ in (7), contributed by the special element Pred $_{\mathrm{i}}$ in (6). In addition, as the informal paraphrase in (8b) suggests, in order to derive the event-distributive reading from the semantics in (6)-(7), Zimmermann (2002) must assume that events are of type $e$, and are not of their own semantic type $\varepsilon$. Finally, it must be mentioned that Zimmermann's syntactic analysis in (6) posits no special relationship between distributive numeral morphology and numerals. Consequently, the account wrongly predicts that the morphology deriving a distributive numeral should be able to combine with bare NPs like 'fish' (see (27) below).

A third general approach to distributive numerals makes use of the special formal machinery provided by the Dynamic Plural Logic (DPIL) framework (van den Berg 1996). Although the accounts vary greatly in their details, such approaches to distributive numerals and distance distributivity can be found in the work of Henderson (2011) and Dotlačil (2012), with important precursors in the work of Farkas (1997) and Brasoveanu \& Henderson (2009). Unfortunately, due to the technical complexity of the DPIL framework, I can offer only the barest sketch of the general structure of these accounts.

In brief, DPIL is a dynamic semantic framework, one that analyzes the meaning of a sentence in terms of the effect that it has upon the linguistic context. Such contexts are in DPIL modeled as sets of sets of variable assignments $G$. Thus, the meaning of a sentence is modeled as a relation between such sets $G, G^{\prime}$. A sentence/discourse is held to be true if its meaning can relate an initial, empty context $G_{0}$ to some other context $G$ '. The primary advantage of this framework is that the complex model structure provided by the sets of sets $G$ allows one to model dependencies between quantificationally bound variables in discourse. Furthermore, it is possible to write formulae in the logical language of DPIL that enforce such dependencies. For this reason, it is possible in this framework to develop a lexical entry for distributive numerals

\footnotetext{
7 The analysis developed by Champollion (2012) is quite different from Zimmermann's, but is nevertheless also subject to these same criticisms. For example, Champollion's semantics - sketched below - relies upon a special morpho-syntactic mechanism of 'theta indexing', so that the distributive operator targets specific theta roles:

(i) $\quad\left[\left[D I S T-\boldsymbol{\theta}_{\mathrm{C}}\right]\right]=\left[\lambda \mathrm{P}_{<, \mathrm{t}}: \lambda \mathrm{e}_{\mathrm{s}}: \mathrm{e} \in \mathrm{e}^{*}\left\{\mathrm{e}^{\prime}: \mathrm{P}\left(\mathrm{e}^{\prime}\right) \& \mathrm{C}\left(\boldsymbol{\theta}\left(\mathrm{e}^{\prime}\right)\right)\right\}\right]$

Moreover, in order to obtain event-distributive readings, Champollion proposes that the function $\tau$ mapping an event to its 'run-time' is a species of theta role. Given the semantics in (i), where the variable $C$ is a contextually salient property, this (non-standard) assumption regarding $\tau$ entails that such 'run-times' must be of the same semantic type as entities. Thus, under Champollion's account, the event-distributive construal again impedes standard type-driven interpretation. Finally, as the interested reader can confirm, Champollion (2012) shares Zimmermann's (2002) faulty prediction that distributive numeral morphology should be able to combine with bare NPs like 'fish'.
} 
that predicts the key semantic effects observed in (1)-(4), without necessarily appealing to special syntactic principles or rules of semantic composition. Consequently, analyses of distributive numerals making use of this framework - such as those developed by Henderson (2011) and Dotlačil (2012) - effectively avoid all the problems noted for Oh (2001, 2005), Zimmermann (2002), and Champollion (2012).

Of course, these analytic advantages come at the cost of the DPIL framework itself, which as noted above, relies upon numerous special assumptions concerning the representation of the context, the nature of linguistic meaning, and the semantics of quantificational binding. Again, space precludes a full description here, but the interested reader is referred to Brasoveanu (2008). It should be noted that what truly distinguishes DPIL from other dynamic semantic frameworks is its use of sets of sets of variable assignments to model linguistic contexts. As a consequence of this, DPIL is formally and computationally far more complex than other dynamic frameworks. It would therefore be preferable to avoid the full power of the DPIL machinery, if at all possible, in the analysis of distributive numerals.

In summary, prior analyses of distributive numerals have required significant complications to the theory of the syntax-semantics interface. In contrast, the analysis developed here rests purely on relatively basic assumptions that are commonplace in the semantic literature on plurality and events. Furthermore, to my knowledge, all prior analyses of distributive numerals treat the ability of sentences like (3b) to describe both participant- and eventdistributive scenarios as a kind of ambiguity (Gil 1982, Oh 2001, Zimmermann 2002, Oh 2005, Balusu 2006, Champollion 2012). That is, under previous accounts, the ability for (3b) to describe both the scenarios in (4) is captured by mapping (3b) to two different sets of truth conditions. ${ }^{8}$ However, I will argue that Tlingit sentences like $(3 \mathrm{~b})$ are not truly ambiguous. That is, I will show that such sentences can be given a single, general set of truth-conditions that covers both the scenarios in (4). Furthermore, we will see that this univocal semantics can also predict a number of more subtle facts regarding distributive numerals in Tlingit, Korean, German, and Kaqchikel (Mayan). Finally, we will see that a small change to the proposed semantics yields a novel analysis of the English binominal each construction, one that predicts certain curious differences between binominal each and canonical distributive numerals.

The remainder of this paper is structured as follows. Section 2 provides some basic background regarding the Tlingit language, and also explains how the original data appearing in this paper were collected. In Section 3, I discuss the morphosyntax of distributive numerals in Tlingit, showing in particular that such numerals can serve either as adverbial or adnominal modifiers. Section 4 introduces the core semantic properties of the construction. Amongst other facts, I show here that the syntactic attachment site of the distributive numeral has no effect upon the kind of distributive scenario the sentence describes. That is, no matter whether the distributive numeral is adverbial or adnominal, the sentence may be true in either participantdistributive or event-distributive scenarios. Section 5 presents the formal semantic and syntactic analysis of Tlingit distributive numerals. In Section 6, we see how the proposed analysis could explain certain puzzles concerning distributive numerals in other languages, while Section 7 discusses the possible treatment of binominal each in English.

\footnotetext{
8 Anna Szabolcsi (p.c.) reports that an earlier, unpublished draft of Balusu 2006 did not rely upon semantic ambiguity to capture these facts, and instead developed an analysis quite close to the one developed in Section 5 .
} 


\section{Linguistic and Methodological Background}

The Tlingit language (Lingít) is the traditional language of the Tlingit people of Southeast Alaska, Northwest British Columbia, and Southwest Yukon Territory. It is the sole member of the Tlingit language family, a sub-branch of the larger Na-Dene language family (Campbell 1997, Mithun 1999, Leer 2010). It is thus distantly related to the Athabaskan languages (e.g., Navajo, Slave, Hupa), and shares their complex templatic verbal morphology (Leer 1991). As mentioned in Footnote 6, I will largely be suppressing this complex structure in my glossing of Tlingit verbs.

Tlingit is a highly endangered language. While there has been no official count of fully fluent speakers, it is privately estimated by some that there may be less than 200 (James Crippen (Dzéiwsh), Lance Twitchell (X'unei), p.c.). Most of these speakers are above the age of 70, and there is no known native speaker below the age of 50 (Dauenhauer \& Dauenhauer 1987). There are extensive, community-based efforts to revitalize the language, driven by a multitude of Native organizations and language activists too numerous to list here. Thanks to these efforts, some younger adults have acquired a significant degree of fluency, and there is growing optimism regarding a new generation of native speakers.

Unless otherwise noted, all data reported here were obtained through interviews with native speakers of Tlingit. Five fluent Tlingit elders participated: Beatrice Brown (Sa.áaxw), Margaret Dutson (Chiksháani), Selena Everson (Kaséix $)$, William Fawcett (Kóoshdaakwwísh), and Helen Sarabia (Káachku.aakw). All five were residents of Juneau, AK at the time of our meeting, and are speakers of the Northern dialect of Tlingit (Leer 1991). Three to four elders were present at each of the interviews, which were held in a classroom at the University of Alaska Southeast in Juneau, AK.

The linguistic tasks presented to the elders were straightforward translation and judgment tasks. The elders were presented with various scenarios, paired with English sentences that could felicitously describe those scenarios. The scenarios were described orally to the elders, and also represented pictorially, through the use of cartoons like the following. 


\section{Sample of the Cartoons Used During Interviews}

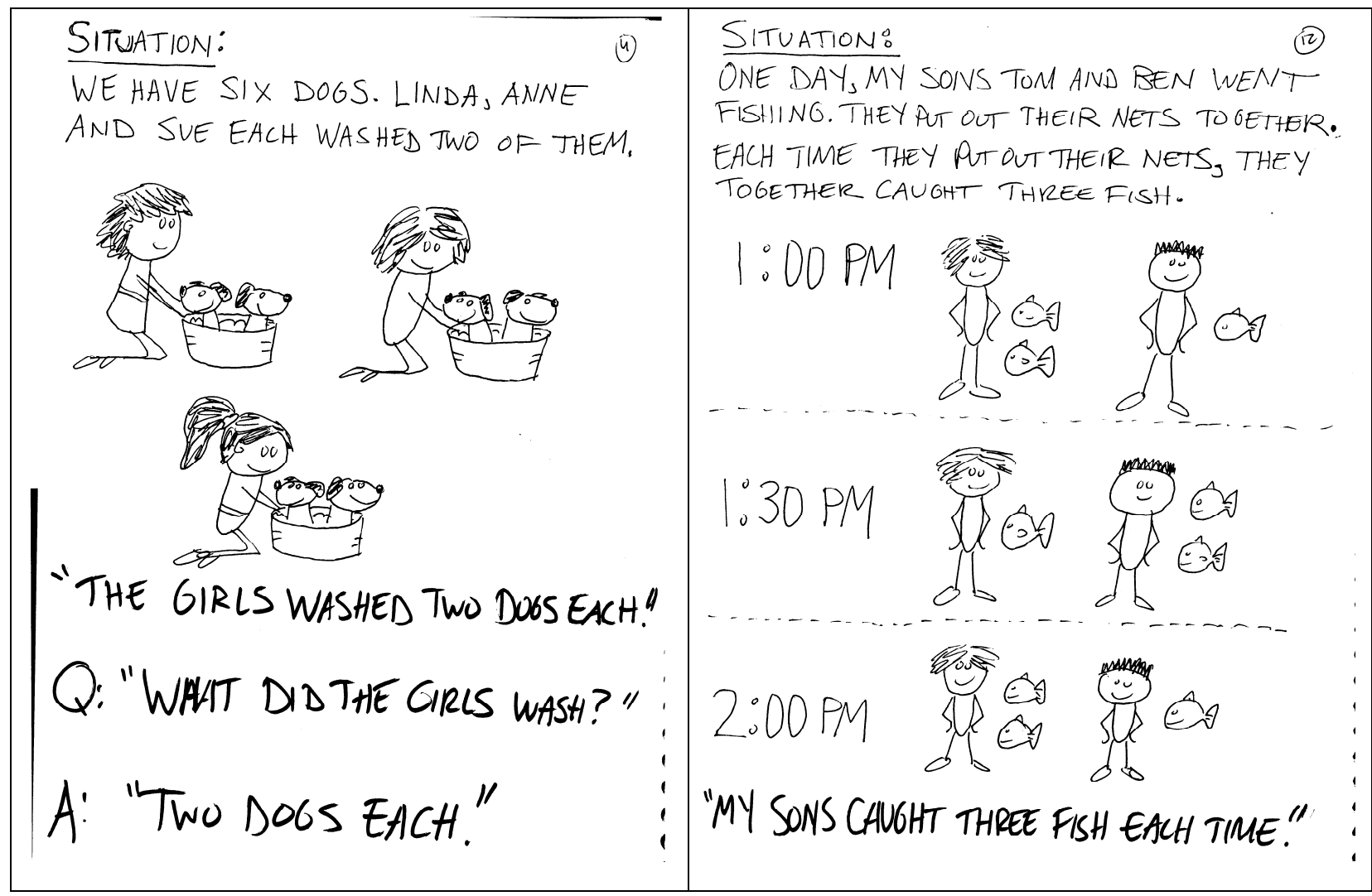

The elders were asked to freely describe the scenarios, as well as to translate certain targeted English sentences describing them. In order to more systematically study their semantics, sentences containing distributive numerals were explored using truth/felicity judgment tasks, a foundational methodology of semantic fieldwork (Matthewson 2004). The elders were thus asked to judge the 'correctness' (broadly speaking) of various Tlingit sentences relative to certain scenarios. The sentences evaluated were either ones offered earlier by the speakers for other scenarios, or ones constructed by myself and judged by the speakers to be 'natural sounding' and correct for other scenarios. As mentioned in Footnote 5, I will notationally distinguish constructed examples from ones uttered spontaneously by the elders.

Finally, it should be noted that unless otherwise indicated, all speakers agreed upon the reported status of the sentences presented here.

\section{The Morphology and Syntax of Distributive Numerals in Tlingit}

As documented by Leer et al. (2001: 26), distributive numerals are formed in Tlingit by suffixing -gáa to the base of the unmarked numeral. As with many suffixes in Tlingit, this distributive suffix bears a tone opposite to that of the immediately preceding syllable. Moreover, for the numerals 1-3, certain phonological changes take place to the numeral root. The numerals 1-5 (for non-humans) are illustrated below. 


\begin{tabular}{ll} 
a. & \multicolumn{2}{l}{ Unmarked } & Numerals \\
\cline { 2 - 2 } tléix' & one \\
déix & two \\
nás'k & three \\
daax'oon & four \\
keijín & five
\end{tabular}

b. Distributive Numerals

\begin{tabular}{ll}
\hline tlék'gaa & one by one, one each \\
dáxgaa & in twos, two each \\
nás'gigáa & in threes, three each \\
daax'oongáa & in fours, four each \\
keijíngaa & in fives, five each
\end{tabular}

Numerals modifying human nouns in Tlingit appear with a 'human classifier' suffix -náx (11a). Similarly, when distributive numerals modify a human noun, they also take the classfier -náx. As illustrated in (11b), the classifier -náx, appears to the right of the distributive suffix -gáa.

\section{(11) Human Distributive Numeral Series in Tlingit (Leer et al. 2001: 26)}

\begin{tabular}{ll} 
a. & \multicolumn{3}{l}{ Unmarked Numerals } \\
\hline tléináx & one \\
dáxnáx & two \\
nás'gináx & three \\
daax'oonináx & four \\
keijínináx & five
\end{tabular}
b. Distributive Numerals tlék'gaanáx one by one, one each dáxgaanáx in twos, two each nás'gigáanáx in threes, three each daax'oongáanáx in fours, four each keijíngaanáx in fives, five each

Distributive numerals are exceedingly rare in natural speech. The few examples that occur in published Tlingit texts appear to have an adverbial syntax, as illustrated below.

\section{Tlék'gaanáx $\quad$ áwé has wuduwaxooox. one.DIST.HUM FOC 3plS.3O.call}

'They called them one by one.'

(Edwards 2009: 260)

Given that all languages allow distributive numerals to function as adverbs (Gil 1982), the possibility and prevalence of adverbial structures like (12) is not surprising. In many languages, however, distributive numerals can also function as adnominal modifiers (Gil 1982, Choe 1987, Zimmermann 2002, Oh 2005, Balusu 2006). Interestingly, it is not unusual to find Tlingit distributive numerals in positions where they appear as if they could be adjoined to a noun. For example, note the surface similarity between (3a) and (3b) above, where the former contains an unmarked numeral that is undoubtedly an adnominal modifier. This raises the question of whether distributive numerals in Tlingit can also, as in other languages, attach adnominally. Unfortunately, given the freedom of word order in the language, there are rather few clear, positive tests for constituency (Cable 2010). Nevertheless, certain facts point towards the conclusion that the language does also possess adnominal distributive numerals.

First, amongst the sentences spontaneously uttered during my interview sessions, several had the form illustrated below. 


\section{Distributive Numerals Preceding Left-Peripheral Nouns}

Nás'gigáa keitl áwé has aawashúch.

three.DIST dog FOC 3plS.3O.bathed

(WF)

'They bathed three dogs each.'

In sentences like (13), the focus particle áwé follows a string consisting of a distributive numeral and a noun. As detailed by Leer (1991), this focus particle optionally marks a phrase occupying a left-peripheral 'focus position'. This raises the question of the attachment site of the distributive numeral. Note that if the numeral were not attached to the noun, then it would have to occupy a separate, unmarked focus position. While it is possible for there to be two left-peripheral 'focus phrases' within a single clause, such structures are rather marked and uncommon (Leer 1991: 23); moreover, in such structures, the initial focus phrase is almost always a sentence connective (Leer 1991: 23). Consequently, given the relative frequency of sentences like (13) during my interviews, I conclude that the distributive numerals in such structures most likely have an adnominal attachment site. Supporting this conclusion is the fact that the distributive numeral in these sentences appears to form an intonational unit with the following noun, whereas distinct focus phrases are typically separated by a noticeable break. Incidentally, the ability for distributive numerals and nouns to form intonational units together is supported by the fact that, when considering certain constructed examples, speakers would sometimes repeat such strings to themselves, as clearly independent units.

\section{Distributive Numerals and Nouns Forming Intonational Units}

$$
\begin{array}{llll}
\ldots \text { Dáxgaa } & \text { keitl } \ldots & \ldots \text { dáxgaa } & \text { keitl } \ldots \\
\text { two.DIST } & \operatorname{dog} & \text { two.DIST } & \operatorname{dog}
\end{array}
$$

While it is imperfect evidence, these intonational facts lend credence to the view that distributive numerals can in Tlingit be adnominal modifiers.

This conclusion is also supported by several basic (though imperfect) syntactic diagnostics. First, speakers report that it is possible to conjoin together two strings consisting of a distributive numeral followed by a bare NP.

\section{Conjunction Test for Constituency with Distributive Numerals and NPs}

Scenario: My sons went to the store to buy some apples and some potatoes. Each one bought two apples and three potatoes.

$$
\begin{aligned}
& \text { [ [ Dáxgaa x'áax'] ka [ nás'gigáa k'únts'] ] áwé has aawa.oo. } \\
& \text { two.DIST apple and three.DIST potato FOC 3plS.3O.bought }
\end{aligned}
$$

They bought two apples each and three potatoes each.

The acceptability of such conjunction structures is a necessary (though not always sufficient) condition for constituency, and so supports the view that Tlingit distributive numerals can function as adnominal modifiers. Similar supporting evidence rests in the ability for distributive 
numerals to appear in elliptical answers to wh-questions. As illustrated in (16b) and (17b), the answer to a wh-question can consist of a distributive numeral followed by a noun.

(16) Distributive Numerals in Elliptical Answers

a. Question Prompt:

$\begin{array}{lllll}\text { Daa sáwé } & \text { has aawasháat. } & \text { yá } & \text { i káa yátx'i? (C) } \\ \text { what } & \text { Q.FOC } & \text { 3plS.3O.caught } & \text { these } & \text { your male children }\end{array}$

'What did your sons catch?'

b. Possible Elliptical Answers
(i) Nás'k xáat
(C)
(ii)
$\begin{array}{ll}\text { Nás'gigáa } & \text { xáat } \\ \text { three.DIST fish }\end{array}$
'Three fish.'
'Three fish each.'
(C)

\section{(17) Distributive Numerals in Elliptical Answers}
a. Question Prompt:
Daa sáwé
what Q.FOC
has aawashúch
wé shaax'wsáani?
those girls
'What did the girls bathe?'
b. $\quad$ Possible Elliptical Answers
(i) Déix keitl (C)
two dogs
'Two dogs'
(ii)
$\begin{array}{ll}\text { Dáxgaa } & \text { keitl } \\ \text { two.DIST } & \text { dog }\end{array}$
'Two dogs each'

Importantly, although speakers report that the discourses in (16) and (17) sound relatively natural, they emphatically reject the discourse in (18b)-(18c) below. That is, an elliptical answer to a wh-question cannot consist of an adverb followed by a noun, as in (18c).

\section{(18) Elliptical Answers in Tlingit Must be Constituents}
a. Target Sentence: Tláakw útlxi quickly boiled.fish 1sgS.3O.ate
(C)
'I ate the utlxi (boiled fish) quickly'.
b. Question Prompt: Daa sáwé yeexáa?
what Q.FOC 2sgS.3O.ate
'What did you eat?'
c. Impossible Answer: $\quad \begin{aligned} \text { Tláakw } & \text { útlxi } \\ \text { quickly } & \text { boiled.fish }\end{aligned}$ 
Given the sharp unacceptability of discourses like (18b)-(18c), the acceptability of (16a)-(16bii) and (17a)-(17bii) suggests that the distributive numerals in (16bii) and (17bii) are not adverbs, but rather adnominal modifiers.

One final argument that distributive numerals can be adnominal surrounds the unacceptability of sentences like those in (19).

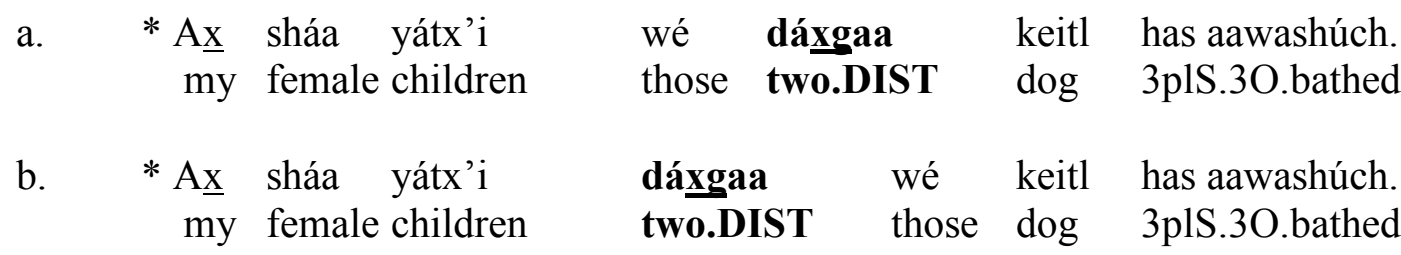

The ill-formedness of $(19 a, b)$ demonstrates that distributive numerals in Tlingit cannot directly modify NPs with demonstratives, a feature shared with distributive numerals in many other languages (Zimmermann 2002, Oh 2005). Importantly, there are two means for correcting the sentences in (19). The first is to move the demonstrative DP to a post-verbal position, as in (20).

$\begin{array}{lllllll}\text { Ax } & \text { sháa yátx’i } & \text { dáxgaa } & \text { has aawashúch } & \text { yú } & \text { keitl } & \text { (BB) }\end{array}$

'My daughters bathed those dogs two at a time.'

Note that, given the ill-formedness of $(19 a, b)$, the distributive numeral in (20) must be basegenerated as an adverb, and could not be a 'floated' adnominal modifier of the post-verbal demonstrative DP.

At first glance, the contrast between (19b) and (20) is somewhat puzzling. After all, if distributive numerals can function as adverbs (20), why isn't (19b) accepted under a parse where the distributive numeral is an adverb, as sketched in (21) below?

\section{Unallowable Parse of Sentence (19b)}

[s [DP Ax sháa yátx’i ] [vp [Adverb dáxgaa ] [vp [DP wé keitl ] has aawashúch ] ] my female children two.DIST those dog 3plS.3O.bathed

The answer is that structures like (21) run afoul of a more general principle of Tlingit sentence formation. As detailed by Leer (1991), Tlingit speakers generally prefer to minimize the amount of phrasal material preceding the verb in a sentence. Thus, if there are more than three major constituents in a sentence, there is a very strong preference amongst speakers for at least one of those constituents to appear after the verb, as in (20).

Given this general word-order preference, the second means for improving $(19 \mathrm{a}, \mathrm{b})$ is quite revealing. Speakers have explicitly observed that sentences $(19 a, b)$ become acceptable if one simply omits the demonstrative, as in (22) below.

\footnotetext{
9 The difference between the demonstratives in (19) and (20) is inconsequential; speakers also accepted a constructed sentence identical to (20), but with the demonstrative wé instead of yú. The difference between these two demonstratives is complex, but yú generally indicates greater distance from the speaker (Leer 1991).
} 
Ax $\quad$ sháa yátx'i

my female children

'My daughters bathed two dogs each'. Or, 'My daughters bathed two dogs each time'.

Importantly, the contrast between (19b) and (22) provides further evidence that distributive numerals in Tlingit can be adnominal. After all, if such numerals could only be adverbs, then sentence (22) would necessarily have the dispreferred structure in (21), and there would be no substantive difference between (22) and (19b). However, if distributive numerals can attach to NPs, then sentence (22) would allow the parse in (23) below.

\section{Allowable Parse of Sentence (22) \\ [s [DP A $\underline{x}$ sháa yátx’i ] [vP [DP dáxgaa my female children \\ two.DIST \\ keitl ] has aawashúch ] ] \\ dog 3plS.3O.bathed}

Note that, under this parse, sentence (22) places only two major constituents before the verb, just as in (20). Therefore, (22) does not run afoul of the general word-order preference that militates against (19b). Importantly, though, this explanation requires that the distributive numeral dáxgaa 'two.DIST' and the noun keitl 'dog' can together form a single constituent.

This explanation for the contrast between (19b) and (22) receives further support from the ill-formedness of the following sentences.
a. * A $\underline{x}$ sháa yátx'i my female children
keitl
dáxgaa
has aawashúch.
$\operatorname{dog}$
two.DIST
3plS.3O.bathed
(C)
$\begin{array}{llll}\text { b. } & \text { *áxgaa } & \text { ax } & \text { sháa yátx’i } \\ \text { two.DIST } & \text { my } & \text { female children }\end{array}$
keitl has aawashúch.
dog 3plS.3O.bathed
(C)

When presented the word-orders in (24), speakers strongly rejected them as 'incorrect', and offered the sentence in (22) as a correction. This contrast follows from the account offered above. In (24b), the subject 'my daughters' intervenes between the distributive numeral and the noun keitl 'dog'. Thus, the latter two cannot form a constituent, and so the sentence unacceptably contains three major phrases before the verb. Regarding sentence (24a), note that nearly all adnominal modifiers in Tlingit are pre-nominal (Naish 1966, Leer 1991). ${ }^{10}$ Consequently, it would be natural to assume that adnominal distributive numerals in Tlingit must be pre-nominal as well. Therefore, the distributive numeral in (24a) cannot form a constituent with the NP keitl 'dog', and so the sentence again contains an unacceptable number of pre-verbal constituents. Finally, if it is assumed that distributive numerals can only be adverbs, then the contrast between (22) and (24) becomes obscure. After all, given the freedom of its word-order, adverbs in Tlingit can generally precede the subject or follow the object (Leer 1991).

Taken together, the facts in (13)-(24) indicate that distributive numerals in Tlingit can function as adnominal modifiers. Moreover, the contrast between (19b) and (22) shows that adnominal distributive numerals can attach only to bare NPs, never to DPs headed by demonstratives. This leads to the following generalization, which was noted earlier under (20).

\footnotetext{
10 The only exceptions are a small, closed class of adjectival modifiers, such as tlein 'big' (Naish 1966, Leer 1991).
} 
If a sentence is of the form in (20) - 'Distributive Numeral' > 'Verb' > 'Demonstrative DP' - then the distributive numeral must be adverbial.

This generalization will be used in Section 4 as a diagnostic for showing that a distributive numeral is adverbial, and not adnominal. Furthermore, as we've just seen, the contrast between (19b) and (22) also leads to the generalization in (26).

Diagnostic for Adnominal Distributive Numerals in Tlingit

If a sentence is of the form in (22) - 'Subject' > 'Distributive Numeral' > 'Bare NP' > 'Verb' - then the distributive numeral must be adnominal.

In the following section, I will use this generalization as a diagnostic showing that a distributive numeral is adnominal, rather than adverbial.

Finally, let us briefly note that, although nouns can be modified by distributive numerals, they cannot themselves bear the 'distributive' suffix -gáa (27b). Rather, this suffix is entirely restricted to numerals, and cannot appear upon other cardinality predicates, such as shayadihéini 'many' (27c).

\section{(27) The Distributive Suffix - $\underline{G} a ́ a$ is Specific to Numerals}
$\begin{array}{lll}\text { a. Nás'gigáa } & \text { xáat has aawasháat. } \\ \text { three.DIST fish } & \text { 3plS.3O.caught }\end{array}$
(BB), (WF)
'They caught three fish each.' Or, 'They caught three fish each time.'
b. * Xáatgaa has aawasháat. fish.DIST 3plS.3O.caught ( $\neq$ ‘They each caught fish.')
c. * Shayadihéinigáa $\mathrm{x}$ 'áax' áwé has aawa.oo. many.DIST apple FOC 3plS.3O.bought ( $\neq$ 'They each bought many apples.')

\section{Semantic Description of Distributive Numerals in Tlingit}

A definitional feature of distributive numerals is that they enforce 'distributive' readings of sentences, and rule out both 'collective' and 'cumulative' readings (Gil 1982, Choe 1987, Oh 2005). ${ }^{11}$ It can be easily shown that the same holds for distributive numerals in Tlingit. First, in scenarios like that in (28), where the girls act 'as a team' to wash the dogs together, it is commonly held that the predicate 'bathe two dogs' holds collectively of the subject. Importantly, in such scenarios, only sentence (28a) containing the unmarked numeral déix 'two' is true. Thus, sentence (28a) allows a 'collective' reading while (28b) does not.

\footnotetext{
${ }^{11}$ For more on the distinction between 'collective', 'cumulative', and 'distributive' readings, I refer the reader to various foundational works in the literature on plural semantics: Link 1983, Scha 1984, Lasersohn 1995, Schwarzschild 1996, Landman 2000, Kratzer 2003, Kratzer 2008, Lasersohn 2011.
} 
(28) Scenario: Linda, Anne and Sue together bathed Sparky and Spot (at the same time).

$\begin{array}{lllll}\text { a. Wé shaax'wsáani } & \text { déix } & \text { keitl } & \text { has aawashúch. } \\ \text { those } & \text { girls } & \text { two } & \text { dog } & \text { 3plS.3O.bathed }\end{array}$

'The girls bathed two dogs.' Judgment: True in the scenario above.

b. Wé shaax'wsáani dáxgaa keitl has aawashúch.

those girls two.DIST dog 3plS.3O.bathed

Judgment: Not true in the scenario above

In a similar fashion, it can be shown that Tlingit distributive numerals do not allow for cumulative readings, while unmarked numerals do. For example, in the scenario under (29), the sons catch a total of three fish, but don't (necessarily) work together as a team. The ability for the English sentence 'My sons caught three fish' to describe such a scenario is often attributed to it allowing a 'cumulative' interpretation. Importantly, in such scenarios, the Tlingit sentence containing the unmarked numeral is true (29a), while the one containing the distributive numeral is not (29b).

(29) Scenario: My sons Tom and Ben went fishing. Tom caught two fish. Ben caught one.

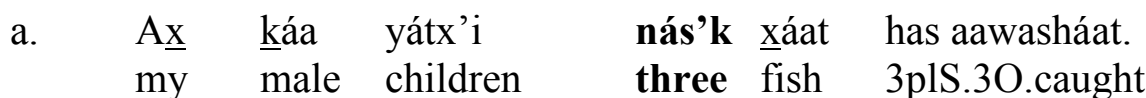

'My sons caught three fish.' Judgment: True in the scenario above.

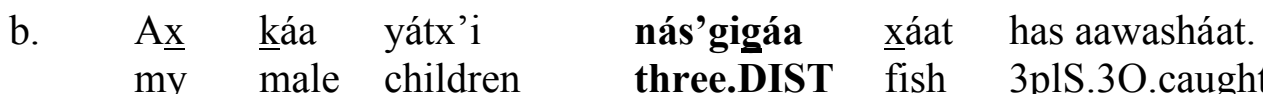

Judgment: Not true in the scenario above

Although distributive numerals do not allow for collective or cumulative readings, they do allow for distributive ones. Indeed, if one ever wishes to express a distributive meaning in Tlingit, then a distributive numeral is virtually obligatory, as shown in (30) and (31) below.

(30) Scenario: We have six dogs. Linda, Anne and Sue each bathed two of them.
a. Wé shaax'wsáani déix keitl has aawashúch.
those girls two dog 3plS.3O.bathed
(BB)
'The girls bathed two dogs.' $\quad$ Judgment: Not true in the scenario above. ${ }^{12}$
$\begin{array}{lllll}\text { b. Wé shaax'wsáani } & \text { dáxgaa } & \text { keitl has aawashúch. } \\ \text { those girls } & \text { two.DIST } & \operatorname{dog} & \text { 3plS.3O.bathed }\end{array}$
(C)
'The girls bathed two dogs each.' Judgment: True in the scenario above.

\footnotetext{
12 There is some evidence to suggest that speakers marginally allow plain numeral sentences like (30a) to receive a distributive reading. First, some speakers initially accepted (30a) as true in this scenario, though they later revised their judgment. In addition, one speaker (WF) offered déix keitl 'two dogs' as the answer to the question Daa sáwé has aawashuch? 'What did they bathe?' under the scenario in (30).
} 
(31) Scenario: My sons Tom and Ben went fishing. Tom caught three fish, and Ben did too.
a. A $\underline{x}$ káa yátx’i
nás'k xáat has aawasháat.
my male children
three fish 3plS.3O.caught
(C)
'My sons caught three fish.'
Judgment: Not true in the scenario above. ${ }^{13}$
b. Ax káa yátx'i nás'gigáa xáat has aawasháat.
my male children three.DIST fish 3p1S.3O.caught
'My sons caught three fish each.' Judgment: True in the scenario above

Let us now recall the definition in (1) of a 'distributive numeral', repeated below. The facts in (28)-(31) indicate that distributive numerals in Tlingit possess the property in (i). Furthermore, the facts in (33) show that such numerals also possess the property in (ii).

\section{Distributive Numeral}

A morphosyntactic construction containing a numeral, whereby (i) the sentence as a whole receives a distributive reading, and (ii) under the allowable readings, the numeral contained within the construction must be interpreted as if it is within the scope of a distributive operator.

\section{(33)}

\section{NP Modified by Distributive Numeral Must be in Scope of Distributive Operator}

Scenario: We have three dogs. Six girls came over to bathe them. Each dog was bathed by a team of two (different) girls.
a. Dáxnáx shaax’wsáani two.HUM girls
nás'gigáa keitl has aawashúch. (HS)
three.DIST dog 3plS.3O.bathed
'Two girls bathed three dogs each.'
Judgment: Not true in this scenario
$\begin{array}{ll}\text { b. Dáxgaanáx } & \text { shaax’wsáani } \\ \text { two.DIST.HUM } & \text { girls }\end{array}$
nás'k keitl has aawashúch.
three dog 3plS.3O.bathed
(HS)
'Three dogs were each bathed by two girls.' Judgment: True in this scenario

The sentences in $(33 a, b)$ differ only in the location of the distributive suffix -gáa; in (33a), it marks the numeral in object position, while in (33b), it appears on the numeral modifying the subject. Importantly, only sentence (33b) is accepted as true in the scenario under (33). Finally, note that a logical representation of this scenario using the distributive operator in (2) would appear as in (34) below.

\footnotetext{
13 As with sentence (30a), some speakers initially accepted (31a) as true in the associated scenario. This suggests that a distributive interpretation of (31a) may be marginally possible.

14 Although (31b) was constructed, sentence (i) below was spontaneously offered as a description of the scenario under (31). In addition, the speaker explicitly translated this sentence back into English as 'They caught three each'
three.DIST fish FOC 3plS.3O.caught
'They caught three fish each.'

(i) Nás'gigáa xáat áwé has aawasháat. (WF)
} 


\section{Representation of the Scenario in (33) Using the Distributive Operator (2)}
$\exists z$. three.dogs(z) \& $\forall \mathrm{x} . \quad \mathrm{x} \leq \mathrm{z} \&$ atom $(\mathrm{x}) \rightarrow \exists$ e. $\exists \mathrm{y}$. two.girls $(\mathrm{y}) \& \mathrm{y}$ bathed $\mathrm{x}$ in $\mathrm{e}$ Restrictor of DIST Scope of DIST

'There is a group of three dogs $z$, and for each atomic member $x$ of $z$, there is an event $e$, and a (possibly different) group of two girls y such that $\mathrm{y}$ bathed $\mathrm{x}$ in e.'

Crucially, under this representation, only the numeral 'two' modifying the subject appears within the scope of the distributive operator; the numeral 'three' modifying the object actually scopes above the operator. Consequently, the contrast between (33a) and (33b) demonstrates that the numeral suffixed with -gáa must be interpreted as if it is within the scope of the distributive operator. Thus, Tlingit distributive numerals indeed exhibit the property in (ii) under (1)/(32).

We have seen that distributive readings of numerals in Tlingit require the presence of the distributive suffix -gáa, and that numerals marked with -gáa must be interpreted as if they scope below a distributive operator. A direct consequence of this, often reported for other languages with distributive numerals (Gil 1982, Oh 2005), is that an 'inverse scope' reading of a transitive sentence with a numerically modified subject is only possible if the subject is modified by a distributive numeral. After all, the hallmark of such 'inverse scope' readings is that the sentence is interpreted as if the subject lies within the scope of a distributive operator, whose restrictor is some NP occupying a position syntactically lower than the subject. The following data illustrate.

\section{Distributive Numerals are Required for Inverse Scope Readings}

Scenario: We have three dogs. Six girls came over to bathe them. Each dog was bathed by a team of two (different) girls.

a. Unmarked Numeral

\begin{tabular}{lcclll}
\hline Dáx́náx & shaax'wsáani & nás'k & keitl & has aawashúch. & (C) ${ }^{15}$ \\
two.HÜM & girls & three & dog & 3plS.3O.bathed \\
'Two girls bathed three dogs.' & & $\underline{\text { Judgment: Not true in scenario above }}$
\end{tabular}

b. Distributive Numeral on Subject

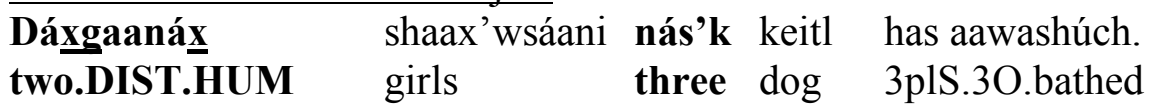

'Three dogs were each bathed by two girls.' Judgment: True in scenario above

In Section 1, we briefly saw that Tlingit sentences containing distributive numerals often appear at first glance to be ambiguous, in that they can often be true in either participantdistributive or event-distributive scenarios. Furthermore, in Section 3, we saw that such sentences in Tlingit can also sometimes be syntactically ambiguous, in that distributive numerals are able to attach both adnominally and adverbially in the language. This naturally raises the question of whether these ambiguities are linked. That is, does the syntactic attachment site of

15 Note that sentence (35a) was strongly rejected in this scenario, even by those speakers who had earlier momentarily accepted the truth of (30a) and (31a) in their associated scenarios. This suggests that distributive readings of unmarked numeral sentences are only possible (marginally) in cases of surface scope. 
the distributive numeral at all affect what kind of distributive scenario the sentence can describe? Interestingly, as in other languages with distributive numerals, the answer appears to be 'no' (Zimmermann 2002, Oh 2005; cf. Gil 1982).

To begin, note that sentences (36a) and (36b) are judged as true in the participantdistributive scenarios they are paired with.

\section{(36) Distributive Numerals and 'Participant-Distributive Scenarios'}

a. Scenario: My sons Tom and Ben went fishing. Tom caught three fish; Ben did too

$$
\begin{array}{llllll}
\text { Ax } & \text { káa } & \text { yátx'i } & \text { nás'gigáa } & \text { xáat } & \text { has aawasháat. } \\
\text { my } & \text { male } & \text { children } & \text { three.DIST } & \text { fish } & \text { 3plS.3O.caught }
\end{array}
$$

Judgment: True in the scenario above

b. Scenario: We have six dogs. Linda, Anne, and Sue each bathed two of them.

Dáxgaa áwé nás'gináx shaax’wsáanich has aawashúch wé keitl (BB) two.DIST FOC three.HUM girls.ERG 3plS.3O.bathed those dog Judgment: True in the scenario above

In scenario (36a), there are three fish to each boy, and in scenario (36b), there are three dogs to each girl. Thus, in each of these scenarios, the distribution is over some plural participant in the sentence, and so they are both participant-distributive scenarios. Importantly, both sentence (36a) and (36b) are judged true in their paired scenario. Furthermore, note that sentence (36a) is of the form 'Subject' $>$ 'Distributive Numeral' $>$ 'Bare NP' $>$ 'Verb'. Consequently, given the generalization in (26), we know that the distributive numeral in (36a) must be adnominal. Moreover, sentence (36b) is of the form 'Distributive Numeral' > 'Verb' > 'Demonstrative DP'. Thus, generalization (25) entails that the distributive numeral in (36b) is adverbial. ${ }^{16}$ Taken together, the facts in (36) show that the attachment site of the distributive numeral does not affect whether the sentence can describe a participant-distributive scenario.

In a similar way, it can be shown that the syntactic status of the distributive numeral does not affect whether the sentence describes an event-distributive scenario.

\section{Distributive Numerals and 'Event-Distributive Scenarios'}

a. $\quad$ Scenario: Every day last week, my sons went out fishing. Every day, they together caught a total of three fish.

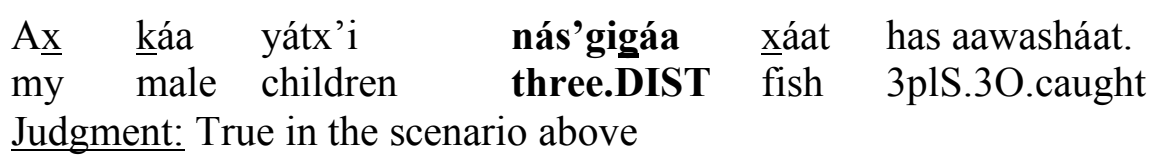

\footnotetext{
16 The adverbial status of dáxgaa 'two.DIST' in (36b) is also ensured by the fact that it does not bear the human suffix -náx, and so could in no way be modifying the subject 'three girls'. Intuitively, it is semantically 'associating' with the demonstrative DP wé keitl 'those dogs'. However, given the facts discussed in Section 3, the distributive numeral could in no way be a 'floated' adnominal modifier of that DP, and so it must be adverbial in (36b).
} 
b. Scenario: My neighbors have eight dogs. My daughters went over to bathe their dogs. First, they together bathed two dogs at the same time. Then, they together bathed another two dogs at the same time. Then, they did another two dogs together, and then another two together, until all eight dogs were bathed.

Ax sháa yátx'i dáxgaa has aawashúch yú keitl (BB) my female children two.DIST 3plS.3O.bathed those dog Judgment: True in the scenario above

In scenario (37a), there are three fish to each event of my sons fishing (but not to each son), and in scenario (37b), there are two dogs to each event of bathing (but not to each daughter). Thus, in each of these scenarios, the distribution is over some plurality of fishing/bathing events, and so they are both event-distributive scenarios. Again, it's important to note that both (37a) and (37b) are true in their paired scenario. Moreover, given generalization (26), we know that (37a) contains an adnominal distributive numeral, while generalization (25) entails that (37b) contains an adverbial distributive numeral. Consequently, the facts in (37) show that both adnominal and adverbial distributive numerals allow readings that cover event-distributive scenarios. Altogether, then, we see from (36) and (37) that the syntactic status of the distributive numeral does not affect the kind of distributive scenario the sentence can describe.

There are, however, other factors that can affect the kinds of scenarios describable by a distributive numeral sentence. In particular, as has been reported for other languages (Gil 1982, Oh 2005), there are certain sentence structures that can only describe event-distributive scenarios. First, note that all the examples considered thus far are transitive sentences containing two plural arguments. Distributive numerals, however, are also possible in transitive sentences containing only one plural argument. As shown below, the only interpretation reported for such sentences describes an event-distributive scenario.

\section{Sentence with a Distributive Numeral and Only One Plural Argument}

Nás'gigáa xáat áwé aawasháat.

three.DIST fish FOC 3sgS.3O.caught

'He caught three fish each time'.

Speaker Comment:

'This means every time he went out - in the morning, in the evening - he caught three'.

Furthermore, it is possible for distributive numerals to appear in intransitive sentences, just so long as the subject is plural. Again, the only interpretation reported is one that describes an event-distributive scenario.

\section{(39) Intransitive Sentence with a Distributive Numeral}

Scenario: We are watching a dance performance. As part of this performance, the girls have divided into pairs. Each pair of girls goes up on stage and dances in turn.
Dáxgaanáx
áwé has aawal'éx.
two.DIST.HUM FOC 3plS.danced
(WF), (BB)
'They danced in twos'. 
Finally, it is possible for a sentence to contain two distributive numerals, each modifying a different NP. As reported for other languages (Gil 1982, Oh 2005), such sentences are judged to be awkward and difficult to understand. However, the meaning speakers identify for them is one that covers an event-distributive scenario.

\section{Transitive Sentences with Two Distributive Numerals}

Scenario: Our neighbor has a bunch of dogs, which are always very dirty. This week, every time we went over to their house, there were two (different) girls bathing three (different) dogs.

Dáxgaanáx $\quad$ shaax'wsáani nás'gigáa keitl has aawashúch.
two.DIST.HUM girls $\quad$ three.DIST dog 3plS.3O.bathed
'Each time, two girls bathed three dogs'. Or, 'Girls in twos bathed dogs in threes.'
Judgment: True in the scenario above.

The facts discussed thus far constitute the empirical core of this paper. In the following section, I develop a formal semantic analysis of these data, one that builds upon much recent work on the semantics of plurality and pluractionality (Beck \& von Stechow 2007, Kratzer 2008, Henderson 2011). In addition to predicting the core facts above, this analysis can also account for certain interesting patterns observed for distributive numerals in other languages, and offers a novel perspective on the semantics of the English binominal each construction.

\section{Formal Semantic Analysis}

This section presents the proposed formal semantic analysis of the distributive suffix -gáa in Tlingit. I begin in Section 5.1 with an overview of the key background assumptions.

\subsection{The Key Ingredients}

For reasons of space, much of my discussion here will presuppose some familiarity with the semantic literature on plurality, distributivity, and pluractionality (Lasersohn 1995, Schwarzschild 1996, Beck \& von Stechow 2007, Kratzer 2008). To begin, I assume throughout the following central hypothesis.

(41) The Cumulativity of all Natural Language Predicates (Krifka 1992, Kratzer 2008)

If $\mathrm{P}$ is a lexical item of a natural language, then $[[\mathrm{P}]]$ satisfies the condition below

\section{Cumulativity Condition}

For any entities $\mathrm{x}_{1}, \ldots, \mathrm{x}_{\mathrm{n}}, \mathrm{y}_{1}, \ldots, \mathrm{y}_{\mathrm{n}}$, if $[[\mathrm{P}]]\left(\mathrm{x}_{1}\right) \ldots\left(\mathrm{x}_{\mathrm{n}}\right)=\mathrm{T}$, and $[[\mathrm{P}]]\left(\mathrm{y}_{1}\right) \ldots\left(\mathrm{y}_{2}\right)=\mathrm{T}$, then $[[P]]\left(x_{1}+y_{1}\right) \ldots\left(x_{n}+y_{n}\right)=T$

According to the principle in (41), for any natural language predicate $P$, if $P$ holds between the entities $\mathrm{x}_{1}, \ldots, \mathrm{x}_{\mathrm{n}}$, and holds between the entities $\mathrm{y}_{1}, \ldots \mathrm{y}_{\mathrm{n}}$, then $P$ holds for the plural sums $\left(\mathrm{x}_{1}+\mathrm{y}_{1}\right), \ldots,\left(\mathrm{x}_{\mathrm{n}}+\mathrm{y}_{\mathrm{n}}\right)$. To briefly illustrate, consider the relation 'father of' sketched in (42). 


\section{Illustration of Cumulative Relations}

\begin{tabular}{lll} 
Fathers & 'father of' & Daughters \\
\hline Bill & & Sue \\
Frank & & Jen \\
Bill+Frank & & Sue+Jen
\end{tabular}

Suppose that, as sketched above, Bill is the father of Sue, and Frank is the father of Jen. Intuitively, Bill and Frank are therefore the father(s) of Sue and Jen. The validity of this inference is captured by the cumulativity hypothesis in (41). After all, if 'father of' holds between Bill and Sue, and between Frank and Jen, then (41) entails that - as sketched above 'father of' must also hold between the pluralities Bill+Frank and Sue+Jen. I refer the reader to the works cited above for more background upon the key hypothesis in (41).

As in much work that assumes (41), I will employ an asterisk '*' as a small notational mnemonic, to remind the reader that the predicates in question are all assumed to be 'cumulative', as defined in (41). ${ }^{17}$ Thus, I will employ predicates like ' $\left[\lambda \mathrm{x}:{ }^{*} \operatorname{dog}(\mathrm{x})\right]$ ', where the ' $*$ ' is simply a reminder that this predicate holds both of individual dogs and dog pluralities.

Next, regarding definite plurals, I adopt the commonplace view that definite determiners have the semantics in (43a), where the 'maximality' operator ' $\sigma_{x}$ ' is defined as in (43b).

\section{The Semantics of Definite DPs}

a. $\quad[[$ the $/$ this $/$ that $]]=\left[\lambda \mathrm{P}_{<\mathrm{et}>}: \sigma_{\mathrm{x}} \cdot \mathrm{P}(\mathrm{x})\right]$

b. $\quad$ Definition of the Operator ' $\sigma_{\underline{x}}$ '

(i) Definition of Cumulative Closure:

If $S$ is a set, then $* S$ is the smallest set such that (i) $S \subseteq * S$, and (ii) if $\alpha$ and $\beta \in *^{*}$, then $\alpha+\beta \in * S$

(ii) $\quad \sigma_{\mathrm{x}} \cdot \mathrm{Q}(\mathrm{x}) \quad=_{\mathrm{df}}$

the entity $\alpha$ such that $\alpha \in *\{\mathrm{x}: \mathrm{Q}(\mathrm{x})\}$ and if $\gamma \in *\{\mathrm{x}: \mathrm{Q}(\mathrm{x})\}$, then $\gamma \leq \alpha$

Note that, for purposes of simplicity, I will also ignore here the deictic content of demonstratives, and will treat them as semantically akin to definite determiners. Therefore, a demonstrative DP such as 'those dogs' will denote the entity ' $\sigma_{\mathrm{x}} \cdot{ }^{*} \operatorname{dog}(\mathrm{x})$ ', which equates to the largest possible plurality of dogs.

A third core assumption of my analysis is that verbs are pure (cumulative) relations between events and their internal arguments, as illustrated below.

\section{Verbs are (Cumulative) Relations Between Events and Themes (Kratzer 2008)}
a. $[[$ bathe $]]=\left[\lambda \mathrm{x}_{\mathrm{e}}: \lambda \mathrm{e}_{\mathrm{e}}: *\right.$ bathe $(\mathrm{e}) \& *$ Theme $\left.(\mathrm{e})=\mathrm{x}\right]$
b. $[[$ catch $]]=\left[\lambda \mathrm{x}_{\mathrm{e}}: \lambda \mathrm{e}_{\varepsilon}: * \operatorname{catch}(\mathrm{e}) \& * \operatorname{Theme}(\mathrm{e})=\mathrm{x}\right]$

\footnotetext{
${ }^{17}$ In the broader literature on plurality, the '*' -operator creates a cumulative predicate from a non-cumualtive one.
} 
Thus, if the individual events of 'dog-bathing' are as in (45a), then the relation 'bathe' holds between all the event-dog pairs in (45b).

Illustration of (Cumulative) Verbal Semantics
a. $\quad$ Atomic Events of Bathing
Bathings
$\mathrm{e}_{1}$
$\mathrm{e}_{2}$
$\mathrm{e}_{3}$
Dogs Bathed
Sparky
Spot
Rex
b. Denotation of 'Bathe'$$
\left\{\begin{array}{l}
<\mathrm{e}_{1}, \text { Sparky }> \\
<\mathrm{e}_{2}, \text { Spot }> \\
<\mathrm{e}_{3}, \text { Rex }> \\
<\mathrm{e}_{1}+\mathrm{e}_{2}, \text { Sparky }+ \text { Spot }> \\
<\mathrm{e}_{1}+\mathrm{e}_{3}, \text { Sparky+Rex }> \\
<\mathrm{e}_{2}+\mathrm{e}_{3}, \text { Spot }+ \text { Rex }> \\
<\mathrm{e}_{1}+\mathrm{e}_{2}+\mathrm{e}_{3}, \text { Sparky }+ \text { Spot }+ \text { Rex }>
\end{array}\right\}
$$

Of course, if only the internal argument of a verb is represented in its lexical meaning (44), then additional syntactic means are required to link the verb to its external argument. Following much literature, I will assume that the external argument of the verb is provided by a little- $v$ head, with the semantics below.

\section{The Semantics of Little-v (Kratzer 1996)}

$$
[[v]]=\quad\left[\lambda \mathrm{x}_{\mathrm{e}}: \lambda \mathrm{e}_{\varepsilon}: * \operatorname{Agent}(\mathrm{e})=\mathrm{x}\right]
$$

Assuming the semantic rule of Event Identification in (47), we can derive the meaning in (48b) for the $v \mathrm{P}$ represented in (48a).

\section{The Rule of Event Identification (Kratzer 1996)}

If $\mathrm{X}$ consists of two daughter nodes, $\mathrm{Y}$ and $\mathrm{Z}$, and $\mathrm{Y}$ is of type $<\mathrm{e}, \mathrm{\varepsilon t}>$, while $\mathrm{Z}$ is of type $<\varepsilon t>$, then $[[\mathrm{X}]]=[\lambda \mathrm{x}: \lambda \mathrm{e}:[[\mathrm{Z}]](\mathrm{e}) \&[[\mathrm{Y}]](\mathrm{x})(\mathrm{e})]$

\section{Illustration of the Compositional Semantics}

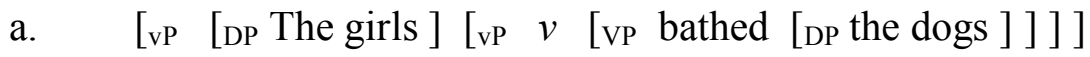
b. $\quad\left[\lambda \mathrm{e}_{\varepsilon}: *\right.$ bathe $\left.(\mathrm{e}) \& * \operatorname{Agent}(\mathrm{e})=\sigma_{\mathrm{x}} \cdot{ }^{*} \operatorname{girl}(\mathrm{x}) \& * \operatorname{Theme}(\mathrm{e})=\sigma_{\mathrm{y}} * \operatorname{dog}(\mathrm{y})\right]$

To briefly unpack the meaning in (48b), note that the metalanguage predicates '*bathe', '*Agent', and '*Theme' are all cumulative. Consequently, if the individual events of dog bathing are as in (49a) below, then the cumulative relations in (49b) will all hold. 
a.

\begin{tabular}{ccl} 
Individual Bathings & Agent & Theme \\
\hline $\mathrm{e}_{1}$ & Jen & Sparky \\
$\mathrm{e}_{2}$ & Sue & Spot \\
$\mathrm{e}_{3}$ & Laura & Rex
\end{tabular}

b. (i) *bathe $\left(\mathrm{e}_{1}+\mathrm{e}_{2}+\mathrm{e}_{3}\right)$

(ii) $\quad * \operatorname{Agent}\left(\mathrm{e}_{1}+\mathrm{e}_{2}+\mathrm{e}_{3}\right)=$ Jen+Sue+Laura $\quad\left(=\sigma_{\mathrm{x}} \cdot{ }^{*} \operatorname{girl}(\mathrm{x})\right)$

(iii) $\quad *$ Theme $\left(\mathrm{e}_{1}+\mathrm{e}_{2}+\mathrm{e}_{3}\right)=\operatorname{Sparky}+\operatorname{Spot}+\operatorname{Rex} \quad\left(=\sigma_{\mathrm{y}} * \operatorname{dog}(\mathrm{y})\right)$

Finally, since the plurality Jen+Sue+Laura is equivalent to ' $\sigma_{\mathrm{x}} \cdot{ }^{*} \operatorname{girl}(\mathrm{x})$ ' and Sparky+Spot+Rex is ' $\sigma_{\mathrm{y}} * \operatorname{dog}(\mathrm{y})$ ', it therefore follows that the plural event $\mathrm{e}_{1}+\mathrm{e}_{2}+\mathrm{e}_{3}$ would satisfy predicate (48b).

Having provided a semantics for the $v P$ in (48a), let us now consider the semantics of the sentence containing it. For purposes of simplicity, I will ignore tense and aspect in this paper. Indeed, the only assumption I will make concerning the sentence as a whole is the following.

\section{Existential Closure of the Event Argument}

Above the $v \mathrm{P}$, there is an existential binder over the event argument.

Consequently, the sentence in (51a) will be assumed to have the LF in (51b), and thus the truthconditions in $(51 \mathrm{c})$.

\section{(51) Illustration of the Semantics}

a. The girls bathed the dogs.

b. LF Structure: $[\mathrm{s}$ ヨe $[\mathrm{vP}[\mathrm{DP}$ The girls $][\mathrm{vP} \quad v$ [vP bathed [DP the dogs $]]]]]$

c. $\quad$ Truth-Conditions: $\quad \exists$ e . $*$ bathe $(\mathrm{e}) \& * \operatorname{Agent}(\mathrm{e})=\sigma_{\mathrm{x}} \cdot{ }^{*} \operatorname{girl}(\mathrm{x}) \&$

$$
* \text { Theme }(e)=\sigma_{\mathrm{y}} * \operatorname{dog}(\mathrm{y})
$$

Now, recall that under the scenario in (49a), the predicate in (48b) holds of the plural event $\mathrm{e}_{1}+\mathrm{e}_{2}+\mathrm{e}_{3}$. Consequently, we predict that the existential truth-conditions in (51c) will also be true in that scenario. Thus, our semantics correctly predicts that sentence (51a) will be true in a scenario where (i) Jen bathes Sparky, (ii) Sue bathes Spot, and (iii) Laura bathes Rex.

The assumptions presented above are by no means unique in the semantic literature on plurality. However, there are three additional ingredients required by my analysis, which are relatively novel. The first is the metalanguage predicate 'Participant', defined as follows.

\section{The Predicate 'Participant'}

$$
\begin{array}{lll}
\text { Participant }(\mathrm{e}, x) & \text { iff } & \mathrm{x} \text { bears a 'theta relation' to } \mathrm{e} \\
& \text { iff } & \mathrm{x} \text { is Agent of } \mathrm{e}, \text { or } \mathrm{x} \text { is Theme of } \mathrm{e}, \text { or } \mathrm{x} \text { is Goal of } \mathrm{e}, \ldots
\end{array}
$$


That is, the predicate 'Participant' will hold between any event and some thematic participant in that event, i.e., its Agent, its Theme, its Goal, etc.

The second additional ingredient is the binary 'maximality' operator ' $\sigma_{<x, y>}$ ', defined below (cf. (43b)).

\section{Binary Maximality Operator}
a. $\quad$ Pair Addition:
$\left.\left.<\mathrm{x}_{1}, \mathrm{x}_{2}\right\rangle+<\mathrm{y}_{1}, \mathrm{y}_{2}\right\rangle=\mathrm{df}_{\mathrm{df}} \quad\left\langle\mathrm{x}_{1}+\mathrm{y}_{1}, \mathrm{x}_{2}+\mathrm{y}_{2}\right\rangle$
b. $\quad \sigma_{<\mathrm{x}, \mathrm{y}>} \cdot \mathrm{Q}(\mathrm{x})(\mathrm{y}) \quad=_{\mathrm{df}}$
the pair $<\alpha, \beta>$ such that $<\alpha, \beta>\in *\{<\mathrm{x}, \mathrm{y}>: \mathrm{Q}(\mathrm{x})(\mathrm{y})\}$, and if $<\gamma, \delta>\in *\{<\mathrm{x}, \mathrm{y}>: \mathrm{Q}(\mathrm{x})(\mathrm{y})\}$, then $\gamma \leq \alpha$, and $\delta \leq \beta$

To define the operator ' $\sigma_{<x, y>}$ ', we first define the ' + ' operator in (53a) for pairs (Krifka 1992, Kratzer 2008). Under this definition, the sum of the pair $\left\langle\mathrm{x}_{1}, \mathrm{x}_{2}\right\rangle$ and the pair $\left\langle\mathrm{y}_{1}, \mathrm{y}_{2}\right\rangle$ is the pair $\left\langle\mathrm{x}_{1}+\mathrm{y}_{1}, \mathrm{x}_{2}+\mathrm{y}_{2}\right\rangle$. With this in place, we can define the expression ' $\left.\sigma_{<\mathrm{x}, \mathrm{y}}\right\rangle . \mathrm{Q}(\mathrm{x})(\mathrm{y})$ ' ' in (53b) as being the sum of all the pairs in $\{<\mathrm{x}, \mathrm{y}>: \mathrm{Q}(\mathrm{x})(\mathrm{y})\}$. For example, in the scenario sketched in (49a), the formula ' $\sigma_{<e}, y>$. *bathe(e) \& Theme(e) = y' would be equal to ' $<e_{1}$, Sparky $>+<e_{2}$, Spot $>+<\mathrm{e}_{3}$, Rex $>$ ', and so would be the pair ' $<\mathrm{e}_{1}+\mathrm{e}_{2}+\mathrm{e}_{3}$, Sparky+Spot + Rex $>$ '.

Finally, following Scha (1984) and Krifka (1990), I assume that there is a distinct type ' $\mathrm{n}$ ' of integers, and that numerals are expressions type $\mathrm{n}$, as follows.

\section{An Integer Semantics for Numerals (Scha 1984, Krifka 1990)}

$\begin{array}{llll}\text { a. } & {[[\text { one }]]} & = & 1 \\ \text { b. } & {[[\text { two }]]} & = & 2 \\ \text { c. } & {[[\text { three }]]} & = & 3\end{array}$

With these ingredients in place, we can now examine the proposed semantics for Tlingit distributive numerals.

\subsection{The Semantics of Distributive Numerals in Tlingit}

To begin, I assume that the distributive suffix -gáa in Tlingit is lexically ambiguous. That is, there are two homophonous -gáa suffixes, one creating adverbial distributive numerals, and the other creating adnominal distributive numerals. While this proposed ambiguity might justly be criticized, there are two difficult challenges facing any attempt at a fully unified semantics for adnominal and adverbial distributive numerals. The first is simply that many languages with adverbial distributive numerals do not permit them to be adnominal modifiers, and vice versa (Gil 1982, Oh 2005). Consequently, an analysis that predicts all adverbial distributive numerals to also function as adnominal modifiers would seem to drastically overgenerate. The second challenge is simply that $v$ Ps and NPs have quite different semantic types $-<\varepsilon t>$ and $<$ et $>-$ and so 
any unified analysis of adverbial and adnominal distributive numerals would per force need to appeal to specialized composition rules, undermining its presumed elegance. ${ }^{18}$

For these reasons, I will assume that there is a distinct distributive suffix $-g a a_{A D V}$ in Tlingit with the semantics below. ${ }^{19}$

\section{Semantics for Adverbial Distributive Numerals}

$$
\begin{aligned}
& {\left[\left[-g a ́ a A_{A D V}\right]\right]=} \\
& {\left[\lambda \mathrm{n}_{\mathrm{n}}:\left[\lambda \mathrm{P}_{<\mathrm{e}, \mathrm{t}}>:\left[\lambda \mathrm{x}_{\mathrm{e}}:\left[\lambda \mathrm{e}_{\varepsilon}: \mathrm{P}(\mathrm{x})(\mathrm{e}) \&\right.\right.\right.\right.} \\
& \left.<\mathrm{e}, \mathrm{x}>=\sigma_{<\mathrm{e}}, \mathrm{y}>\mathrm{y}<\mathrm{x} \&|\mathrm{y}|=\mathrm{n} \& \mathrm{e}^{\prime}<\mathrm{e} \& \operatorname{Participant}\left(\mathrm{e}^{\prime}, \mathrm{y}\right)\right] \ldots \text { ] }
\end{aligned}
$$

The explicit examples below will help to clarify the content of this lexical entry. For the moment, however, we can break down the meaning in (55) as follows. The adverb-creating -gáa suffix takes as argument an integer ' $\mathrm{n}$ ' and a relation ' $\mathrm{P}$ ' between entities and events, and then returns a relation between entities and events, which holds of an entity ' $x$ ' and an event ' $e$ ' iff (i) the relation ' $\mathrm{P}$ ' holds between ' $\mathrm{x}$ ' and ' $\mathrm{e}$ ', and (ii) the pair $<\mathrm{e}, \mathrm{x}\rangle$ is the sum of those pairs $<\mathrm{e}$ ', $\mathrm{y}\rangle$ such that (a) $y$ is a proper part of $x$, and (b) $y$ is a plurality of cardinality of $n$, (c) e' is a proper part of e, and (d) y is a participant in e'.

To get a better handle on this denotation, let us consider the sentence in (56a) below. Given generalization (25), the distributive numeral dáxgaa in (56a) is adverbial. Moreover, following Beck \& von Stechow's (2007) analysis of the English adverb 'one by one', I will assume that the structure in (56b) is a possible LF for (56a). Under this LF structure, the DP $y u$ ' keitl 'those dogs' undergoes movement, creating the lambda operator ' 1 ' (Heim \& Kratzer 1998). This movement of the direct object is followed by a 'tucking-in' movement of the distributive numeral, between the direct object and the lambda that its movement creates. I refer the reader to Beck \& von Stechow 2007 for more discussion of this LF syntax. Given this LF, however, our semantics in (55) yields the truth-conditions in (56c).

\section{The Compositional Semantics of Adverbial Distributive Numerals}

a. Tlingit Sentence:

A x sháa yátx'i dáxgaa has aawashúch yú keitl (BB) my female children two.DIST 3plS.3O.bathed those dog

\footnotetext{
18 The reader should note that, as shown below, the proposed ambiguity in -gáa will not be used to derive the ability for distributive numerals to describe both participant- and event-distributive scenarios. Consequently, for the reasons outlined above, any account that attempts to derive the facts in (3)-(4) by appealing to ambiguity must actually posit a four-way ambiguity, between (i) adverbial vs. adnominal distributive numeral and (ii) entity vs. event distribution. Again, as shown below, the proposed account avoids positing the ambiguity in (ii), but must still retain the ambiguity in (i).

${ }^{19}$ I would like to note that this semantics is both inspired by and based upon the semantics for pluractional adverbs (e.g. 'one by one') developed by Beck \& von Stechow (2007), as well as the treatment of the German adverb jeweils by Kratzer (2008).
} 


\section{b. LF Structure:}

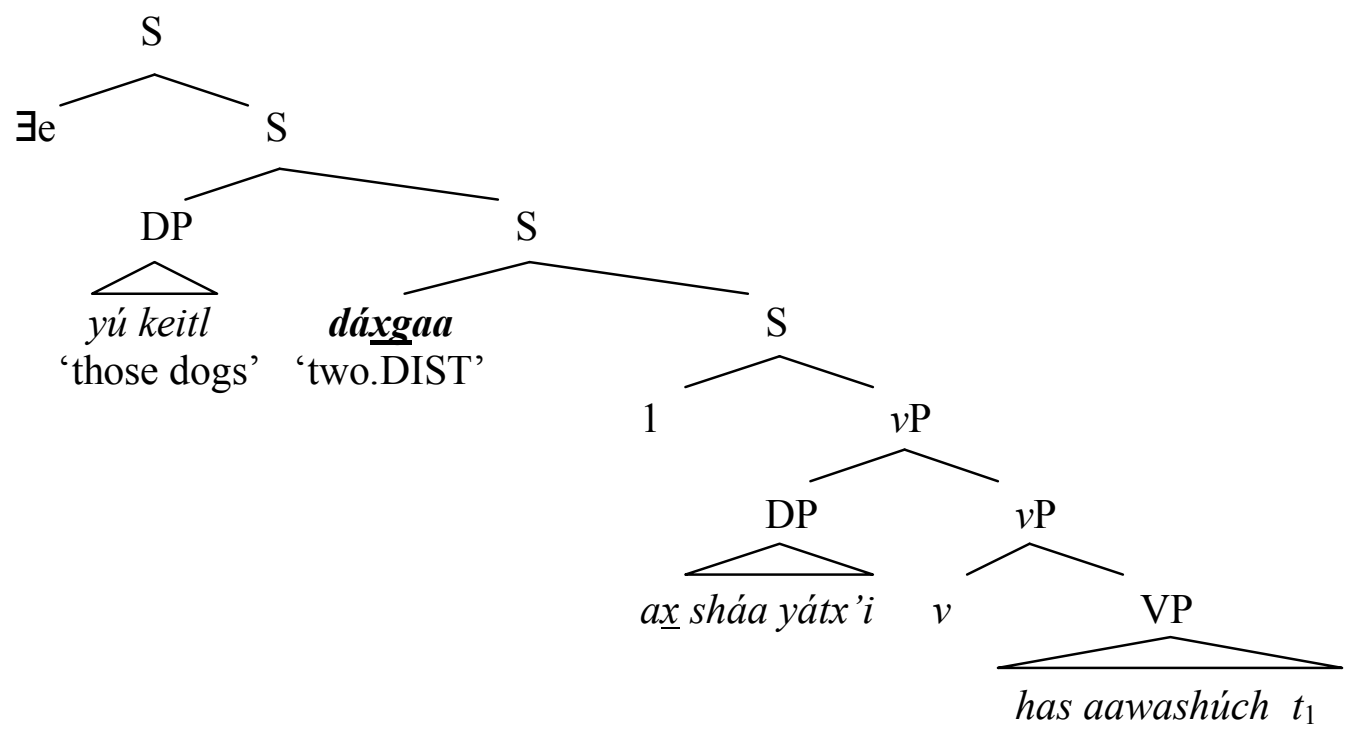

c. $\quad$ Predicted Truth-Conditions:

$$
\begin{aligned}
& \exists \text { Je . *bathe(e) \& *Agent(e) }=\sigma_{\mathrm{x}} *{ }^{*} \text { my.daughter(x) \& } * \text { Theme }(\mathrm{e})=\sigma_{\mathrm{y}} \cdot{ }^{*} \operatorname{dog}(\mathrm{y}) \& \\
& <\mathrm{e}, \sigma_{\mathrm{y}}{ }^{*} \operatorname{dog}(\mathrm{y})>=\sigma_{<\mathrm{e},}, \mathrm{z}>\mathrm{z}<\sigma_{\mathrm{y}}{ }^{*} \operatorname{dog}(\mathrm{y}) \&|\mathrm{z}|=2 \& \mathrm{e}{ }^{\prime}<\mathrm{e} \& \operatorname{Participant}\left(\mathrm{e}^{\prime}, \mathrm{z}\right)
\end{aligned}
$$

My daughters (cumulatively) bathed those dogs, and the dogs are the proper sum of pairs of things that took part in the bathing

Given our assumptions from the previous section, the truth-conditions in (56c) can be read informally as follows: there is a (plural) event e of bathing, whose agent is my daughters and whose theme is the dogs, and the pair consisting of e and the dogs is the sum of those pairs $<e^{\prime}, \mathrm{z}>$ such that $\mathrm{z}$ is a pair of dogs, e' is a proper part of e, and $\mathrm{z}$ participates in e'. Breaking this down still further, we see that these truth-conditions amount to the claim that my daughters cumulatively bathed the dogs, and the dogs can be broken down into pairs, each of which is the theme of some sub-event of the larger event of bathing. While this is still quite a mouthful, consider how it applies to the participant-distributive scenario in (36b), repeated below.

\section{Participant-Distributive Scenario}

We have six dogs. Linda, Anne, and Sue (my daughters) each bathed two of them.

\begin{tabular}{cll} 
Bathings & Agent & Theme \\
\hline $\mathrm{e}_{1}$ & Linda & Sparky+Rex \\
$\mathrm{e}_{2}$ & Anne & Spot+Fido \\
$\mathrm{e}_{3}$ & Sue & Lucky+Lassie
\end{tabular}

Consider the plural event $\mathrm{e}_{1}+\mathrm{e}_{2}+\mathrm{e}_{3}$. Given the assumptions from Section 5.1, it follows that *Agent $\left(\mathrm{e}_{1}+\mathrm{e}_{2}+\mathrm{e}_{3}\right)=$ Linda + Anne + Sue $=\sigma_{\mathrm{x}} \cdot{ }^{*}$ my.daughter(x). Moreover, it follows that $*$ Theme $\left(\mathrm{e}_{1}+\mathrm{e}_{2}+\mathrm{e}_{3}\right)=$ Sparky+Rex+Spot+Fido+Lucky+Lassie $=\sigma_{\mathrm{y}} \cdot{ }^{*} \operatorname{dog}(\mathrm{y})$. Therefore, in scenario (57), the condition ' $\exists \mathrm{e} .{ }^{*}$ bathe(e) $\& * \operatorname{Agent}(\mathrm{e})=\sigma_{\mathrm{x}} \cdot{ }^{*} \mathrm{my} \cdot \operatorname{daughter}(\mathrm{x}) \& *$ Theme $(\mathrm{e})=$ 
$\sigma_{\mathrm{y}} * \operatorname{dog}(\mathrm{y})$, in (56c) holds. Now, consider the pair $<\mathrm{e}_{1}+\mathrm{e}_{2}+\mathrm{e}_{3}$, Sparky+Rex+Spot+Fido+Lucky+Lassie $>$. Note that this pair is the sum of the pairs $\left\{<\mathrm{e}_{1}\right.$, Sparky + Rex $>,<\mathrm{e}_{2}$, Spot + Fido $>,<\mathrm{e}_{3}$, Lucky+Lassie $\left.>\right\}$. Moreover, note that this set of pairs is equal to the set $\left\{\left\langle\mathrm{e}^{\prime}, \mathrm{z}>: \mathrm{z}<\sigma_{\mathrm{y}}{ }^{*} \operatorname{dog}(\mathrm{y}) \&|\mathrm{z}|=2 \& \mathrm{e}^{\prime}<\mathrm{e}_{1}+\mathrm{e}_{2}+\mathrm{e}_{3} \& \operatorname{Participant}\left(\mathrm{e}^{\prime}, \mathrm{z}\right)\right\}\right.$. Therefore, it follows from our definition in (53b) that the pair $<\mathrm{e}, \sigma_{\mathrm{y}} \cdot{ }^{*} \operatorname{dog}(\mathrm{y})>=<\mathrm{e}_{1}+\mathrm{e}_{2}+\mathrm{e}_{3}$, Sparky+Rex+Spot+Fido+Lucky+Lassie $>=\sigma_{<\mathrm{e}, \mathrm{z}>} . \mathrm{z}<\sigma_{\mathrm{y} .} * \operatorname{dog}(\mathrm{y}) \&|\mathrm{z}|=2 \&$ e' $<\mathrm{e} \&$ Participant $\left(\mathrm{e}^{\prime}, \mathrm{z}\right)$. Putting both these observations together, we find that the entirety of the truthconditions in (56c) hold in scenario (57).

Given that the predicted truth-conditions hold in scenario (57), we see that our semantics correctly predicts that sentences containing adverbial distributive numerals are interpreted as true in participant-distributive scenarios. Now let us consider the event-distributive scenario in (37b), repeated below

\section{Event-Distributive Scenario}

My neighbors have eight dogs. My daughters went over to bathe their dogs. First, they together bathed two dogs at the same time. Then, they together bathed another two dogs at the same time. Then, they did another two dogs together, and then another two together, until all eight dogs were bathed.

\begin{tabular}{cll} 
Bathings & Agent & Theme \\
\hline $\mathrm{e}_{1}$ & Linda + Anne + Sue & Sparky + Rex \\
$\mathrm{e}_{2}$ & Linda + Anne + Sue & Spot + Fido \\
$\mathrm{e}_{3}$ & Linda + Anne + Sue & Lucky + Lassie \\
$\mathrm{e}_{4}$ & Linda + Anne + Sue & Ruffles + Toto
\end{tabular}

Intuitively, in this scenario it is again the case that the girls cumulatively bathed the dogs, and the dogs can be broken down into pairs, each of which is theme to some sub-event of the larger (cumulative) bathing. Thus, it would seem our semantics correctly predicts (56a) to be true in scenario (58). We can also see this in more detail as follows. Consider the plural event $\mathrm{e}_{1}+\mathrm{e}_{2}+\mathrm{e}_{3}+\mathrm{e}_{4}$. As before, it is the case that $*$ bathe $\left(\mathrm{e}_{1}+\mathrm{e}_{2}+\mathrm{e}_{3}+\mathrm{e}_{4}\right)$, *Agent $\left(\mathrm{e}_{1}+\mathrm{e}_{2}+\mathrm{e}_{3}+\mathrm{e}_{4}\right)=$ $\sigma_{\mathrm{x}} \cdot *$ my.daughter $(\mathrm{x})$, and $*$ Theme $\left(\mathrm{e}_{1}+\mathrm{e}_{2}+\mathrm{e}_{3}+\mathrm{e}_{4}\right)=\sigma_{\mathrm{y}} * \operatorname{dog}(\mathrm{y})$. Moreover, consider the pair $<\mathrm{e}_{1}+\mathrm{e}_{2}+\mathrm{e}_{3}+\mathrm{e}_{4} \quad, \quad$ Sparky+Rex + Spot+Fido+Lucky+Lassie + Ruffles + Toto $>=<\mathrm{e}_{1}+\mathrm{e}_{2}+\mathrm{e}_{3}+\mathrm{e}_{4}$, $\sigma_{\mathrm{y}} * \operatorname{dog}(\mathrm{y})>$. Clearly, this pair is the sum of the pairs $\left\{<\mathrm{e}_{1}, \operatorname{Sparky}+\operatorname{Rex}>,<\mathrm{e}_{2}, \operatorname{Spot}+\mathrm{Fido}>,<\mathrm{e}_{3}\right.$, Lucky+Lassie $>,<\mathrm{e}_{4}$, Ruffles + Toto $>$ \}. Moreover, note that this latter set is equal to the set $\left\{<\mathrm{e}^{\prime}, \mathrm{z}>: \mathrm{z}<\sigma_{\mathrm{y}} *^{*} \operatorname{dog}(\mathrm{y}) \&|\mathrm{z}|=2 \& \mathrm{e}^{\prime}<\mathrm{e}_{1}+\mathrm{e}_{2}+\mathrm{e}_{3}+\mathrm{e}_{4} \&\right.$ Participant $\left.\left(\mathrm{e}^{\prime}, \mathrm{z}\right)\right\}$. It therefore follows that $<\mathrm{e}_{1}+\mathrm{e}_{2}+\mathrm{e}_{3}+\mathrm{e}_{4}, \sigma_{\mathrm{y}} * \operatorname{dog}(\mathrm{y})>=\sigma_{<\mathrm{e}, \mathrm{z}}>. \mathrm{z}<\sigma_{\mathrm{y}}{ }^{*} \operatorname{dog}(\mathrm{y}) \&|\mathrm{z}|=2 \&$ e' $<\mathrm{e} \&$ Participant(e', $\left.\mathrm{z}\right)$. Putting both these observations together, we find that the entirety of the truth-conditions in (56c) hold in scenario (58).

Thus, we find that our semantics in (55) correctly predicts that sentences like (56a), containing adverbial distributive numerals, will be true both in participant-distributive and eventdistributive scenarios. But, what of sentences containing adnominal distributive numerals? As noted earlier, I will assume that there is a second distributive suffix - gáa $a_{\mathrm{ADN}}$ in Tlingit, which derives adnominal distributive numerals and has the semantics below. 


\section{Semantics for Adnominal Distributive Numerals}

$$
\begin{aligned}
& {\left[\left[- \text { gáa }_{\mathrm{ADN}}\right]\right]=} \\
& {\left[\lambda \mathrm{n}_{\mathrm{n}}:\left[\lambda \mathrm{Q}_{<\mathrm{et}\rangle}:\left[\lambda \mathrm{P}_{<\mathrm{e}, \mathrm{t}}:\left[\lambda \mathrm{e}_{\mathrm{t}}: \exists \mathrm{x} \cdot \mathrm{Q}(\mathrm{x}) \& \mathrm{P}(\mathrm{x})(\mathrm{e}) \&\right.\right.\right.\right.} \\
& \left.\left.<e, x>=\sigma_{<e^{\prime}, y>} . y<x \&|y|=n \& e^{\prime}<e \& \operatorname{Participant}\left(e^{\prime}, y\right)\right] \ldots\right]
\end{aligned}
$$

Again, the proposed semantics is rather complex, but can be broken down as follows. The adnominal -gáa takes as argument an integer ' $\mathrm{n}$ ' and an <et> predicate 'Q', supplied by the modified NP. It then takes as argument a relation ' $\mathrm{P}$ ' between entities and events, and returns a predicate of events. This predicate of events holds of an event ' $e$ ' iff (i) there is an ' $x$ ' such that $\mathrm{Q}(\mathrm{x})$ holds, and the relation ' $\mathrm{P}$ ' holds between ' $\mathrm{x}$ ' and ' $\mathrm{e}$ ', and (ii) the pair $<\mathrm{e}, \mathrm{x}>$ is the sum of those pairs $<e^{\prime}, y>$ such that (a) $y$ is a proper part of $x$, and (b) y is a plurality of cardinality of $n$, (c) e' is a proper part of e, and (d) y is a participant in e'.

As before, we can clarify the content of this proposal through an illustrative example. Consider sentence (60a) below. Given generalization (26), this sentence contains an adnominal distributive numeral. I will assume that this sentence receives the simple, 'surface-faithful' LF structure in (60b), where the NP marked by the distributive numeral remains in situ within the $\nu \mathrm{P}$. With this LF, the semantics in (59) predicts the truth-conditions in (60c).

\section{The Compositional Semantics of Adnominal Distributive Numerals}

a. Tlingit Sentence:

\begin{tabular}{llllll}
\hline Ax & $\underline{\text { káa }}$ & yátx’i & nás'gigáa & xáat & has aawasháat. \\
my & male & children & three.DIST & fish & 3plS.3O.caught
\end{tabular}

b. LF Structure:

[s $\exists \mathrm{e}\left[{ }_{v \mathrm{P}}\right.$ ax $\underline{\text { káa }}$ yátx'i [vp $v$ [vp [ nás'gigáa xáat ] has aawasháat ] ] ] ]

c. $\quad$ Predicted Truth-Conditions:

$\exists$ J $. \exists x . *$ fish $(\mathrm{x}) \& *$ caught(e) \& $* \operatorname{Agent}(\mathrm{e})=\sigma_{\mathrm{y}} \cdot{ }^{*} \mathrm{my} \cdot \operatorname{son}(\mathrm{y}) \& *$ Theme $(\mathrm{e})=\mathrm{x} \&$

$$
<\mathrm{e}, \mathrm{x}>=\sigma_{<\mathrm{e}^{\prime}, \mathrm{z}>} \cdot \mathrm{z}<\mathrm{x} \&|\mathrm{z}|=3 \& \mathrm{e}^{\prime}<\mathrm{e} \& \operatorname{Participant}\left(\mathrm{e}^{\prime}, \mathrm{z}\right)
$$

There are some fish $x$ such that my sons (cumulatively) caught $x$, and $x$ is the proper sum of triplets of things that took part in the catching

As before, we can read the truth-conditions in (60c) informally as follows: there is a (plural) event e of catching, whose agent is my sons and whose theme is a bunch of fish $x$, and the pair consisting of e and $\mathrm{x}$ is the sum of those pairs $\left\langle\mathrm{e}^{\prime}, \mathrm{z}\right\rangle$ such that $\mathrm{z}$ is a triplet of fish, $\mathrm{e}^{\prime}$ is a part of $\mathrm{e}$, and $\mathrm{z}$ participates in e'. Mulling this over a bit, we find that this is equivalent to the claim that my sons cumulatively caught a bunch of fish, and the fish they caught can be broken down into triplets, each of which is the theme of some sub-event of the larger catching event.

Importantly, these predicted truth-conditions will again hold in both participantdistributive and event-distributive scenarios. Consider first the participant-distributive scenario in (36a), repeated below. 


\begin{tabular}{cll} 
Catchings & Agent & Theme \\
\hline $\mathrm{e}_{1}$ & Tom & fish $_{1}+\mathrm{fish}_{2}+\mathrm{fish}_{3}$ \\
$\mathrm{e}_{2}$ & Ben & fish $_{4}+\mathrm{fish}_{5}+\mathrm{fish}_{6}$
\end{tabular}

Intuitively, in this scenario, there is indeed an event $\mathrm{e}_{1}+\mathrm{e}_{2}$ of my sons cumulative catching a bunch of fish, fish $1+\mathrm{fish}_{2}+\mathrm{fish}_{3}+\mathrm{fish}_{4}+\mathrm{fish}_{5}+\mathrm{fish}_{6}$. Moreover, this sextuplet of fish can be broken down into triplets, each of which participated in some subevent of $\mathrm{e}_{1}+\mathrm{e}_{2}$. Thus, under our italicized, informal characterization of the truth-conditions in (60c), they indeed hold in scenario (61). We can also show the validity of (60c) in (61) in more formal detail. As the reader can confirm, the event $\mathrm{e}_{1}+\mathrm{e}_{2}$ witnesses the first sub-part of the truth-conditions in (60c): $\exists \mathrm{e} . \exists \mathrm{x}$. $*$ fish $(\mathrm{x}) \& *$ caught $(\mathrm{e}) \& *$ Agent $(\mathrm{e})=\sigma_{\mathrm{y}} *{ }^{*}$ my.son $(\mathrm{y}) \& *$ Theme $(\mathrm{e})=\mathrm{x}$. Now consider the pair $<\mathrm{e}_{1}+\mathrm{e}_{2}, \mathrm{fish}_{1}+\mathrm{fish}_{2}+\mathrm{fish}_{3}+\mathrm{fish}_{4}+\mathrm{fish}_{5}+\mathrm{fish}_{6}>$. This pair is indeed the sum of the pairs $\left\{<\mathrm{e}_{1}\right.$, fish $_{1}+$ fish $_{2}+$ fish $_{3}>,<\mathrm{e}_{2}$, fish $_{4}+$ fish $_{5}+$ fish $\left._{6}>\right\}$. Moreover, the reader can confirm that this set of pairs is equal to the set $\left\{<\mathrm{e}^{\prime}, \mathrm{z}>: \mathrm{z}<\mathrm{fish}_{1}+\mathrm{fish}_{2}+\mathrm{fish}_{3}+\mathrm{fish}_{4}+\mathrm{fish}_{5}+\mathrm{fish}_{6} \&|\mathrm{z}|=3 \& \mathrm{e}^{\prime}<\mathrm{e}_{1}+\mathrm{e}_{2} \&\right.$ Participant $\left.\left(\mathrm{e}^{\prime}, \mathrm{z}\right)\right\}$. Thus, we find that the equation ' $<\mathrm{e}_{1}+\mathrm{e}_{2}, \mathrm{fish}_{1}+\mathrm{fish}_{2}+\mathrm{fish}_{3}+\backslash \mathrm{fish}_{4}+\mathrm{fish}_{5}+\mathrm{fish}_{6}>$ $=\sigma_{<e^{\prime}, z>} . \mathrm{z}<\mathrm{x} \&|\mathrm{z}|=3 \& \mathrm{e}$ ' $<\mathrm{e} \&$ Participant $\left(\mathrm{e}^{\prime}, \mathrm{z}\right)$ ' holds, and so the entire existential formula in (60c) is witnessed by $\mathrm{e}_{1}+\mathrm{e}_{2}$ and fish ${ }_{1}+\mathrm{fish}_{2}+\mathrm{fish}_{3}+\mathrm{fish}_{4}+\mathrm{fish}_{5}+\mathrm{fish}_{6}$.

Having seen that we predict (60a) to be true in participant-distributive scenarios, let us now consider the event-distributive scenario in (37a), repeated below.

\section{Event-Distributive Scenario}

Every day last week, my sons went out fishing. Every day, they together caught a total of three fish.

\begin{tabular}{clc} 
Catchings & Agent & Theme \\
\hline $\mathrm{e}_{1}$ & Tom+Ben & fish $_{1}+\mathrm{fish}_{2}+\mathrm{fish}_{3}$ \\
$\ldots$ & $\ldots$ & $\ldots$. \\
$\mathrm{e}_{7}$ & Tom+Ben & fish $_{19}+\mathrm{fish}_{20}+\mathrm{fish}_{21}$
\end{tabular}

Again, in this scenario, there is indeed an event $\mathrm{e}_{1}+\ldots+\mathrm{e}_{7}$ of my sons cumulative catching a bunch of fish, fish ${ }_{1}+\ldots+$ fish $_{21}$. Moreover, this plurality of fish can be broken down into triplets, each of which participated in some subevent of $\mathrm{e}_{1}+\ldots+\mathrm{e}_{7}$. It is apparent that under our informal reading of (60c), those truth-conditions hold in the event-distributive scenario above. We could again show in more formal detail that those truth-conditions hold in (62), but in the interest of space, this will be left as an exercise to the reader.

In summary, we have seen that our semantic analysis of distributive numerals in (55) and (59) correctly predicts the core pattern in (36)-(37): the syntactic attachment site of the distributive numeral has no effect upon whether the sentence can describe event-distributive or participant-distributive scenarios. Furthermore, it is important to note that under our analysis, the ability for sentences with distributive numerals to describe both kinds of distributive scenarios is not a case of ambiguity (cf. Gil 1982, Oh 2001, Zimmermann 2002, Oh 2005, Balusu 2006, Champollion 2012). Rather, such sentences simply receive truth-conditions that are general enough to hold in both kinds of distributive scenarios. To put the matter more acutely, our 
semantics in (55)-(59) predicts that a sentence containing the phrase ' $n$-gáa $N P$ ' will be true if there is a plural event that can be divided up into (proper) subevents, each of which contains ' $n$ $N P$ 's in it. Thus, our semantics most directly predicts the truth of such sentences in eventdistributive scenarios. However, crucially, participant-distributive scenarios can themselves actually be viewed as a special subcase of event-distributive scenarios. That is, participantdistributive scenarios are simply event-distributive scenarios where each of the key subevents contains an atomic member of some other plural participant in the event. In this way, a semantics that guarantees that distributive numeral sentences are true in event-distributive scenarios will also capture their truth in participant-distributive ones. Consequently, the proposed analysis unlike previous accounts - is able to capture the core facts in (3)-(4) without mapping sentences like (3b) to multiple sets of truth-conditions, and without having to appeal to a type-ambiguity in the DIST operator ( $c f$. , Oh 2001, 2005) or give up the common assumption that events and entities are of distinct semantic types ( $c f$. , Zimmermann 2002, Champollion 2012).

Thus far, we've seen how the semantics in (55) and (59) operates, and how it derives the key facts in (36)-(37). In the following subsection, we will see that this semantics can also capture a variety of other facts observed for Tlingit distributive numerals.

\subsection{Other Key Features of Tlingit Distributive Numerals}

Although our semantics predicts that Tlingit sentences with distributive numerals can in principle describe both event-distributive and participant-distributive scenarios, we saw at the end of Section 4 that there are certain sentence types in the language that describe only eventdistributive scenarios. Interestingly, our semantics in (55) and (59) predicts this range of facts.

First, let us consider sentences like (38), which contain only one plural NP. As shown below, our semantics predicts such sentences to have the truth-conditions in (63c).

\section{Sentence with a Distributive Numeral and Only One Plural Argument}
a. Sentence: $\quad \underline{x}$ yéet nás'gigáa xáat aawasháat.
My son three.DIST fish 3sgS.3O.caught
'My son caught three fish each time'.
b. $\quad \underline{L F}: \quad\left[\mathrm{s} \exists \mathrm{e}\left[{ }_{v \mathrm{P}}[\mathrm{ax}\right.\right.$ yéet $]\left[{ }_{\mathrm{P}} v[\mathrm{VP}[\right.$ nás'gigáa xáat $]$ aawasháat $\left.\left.\left.\left.]\right]\right]\right]\right]$
c. $\quad$ Predicted Truth-Conditions

$$
\begin{aligned}
& \exists \text { e. } \exists \text { x } . * \text { fish }(x) \& * \text { caught }(\mathrm{e}) \& * \operatorname{Agent}(\mathrm{e})=\text { my.son } \& * \text { Theme }(\mathrm{e})=\mathrm{x} \& \\
& <\mathrm{e}, \mathrm{x}>=\sigma_{<\mathrm{e}}, \mathrm{y}>\cdot \mathrm{y}<\mathrm{x} \&|\mathrm{y}|=3 \& \text { e' }<\text { e \& Participant }\left(\mathrm{e}^{\prime}, \mathrm{y}\right)
\end{aligned}
$$

As should now be familiar to the reader, the truth-conditions in (63c) state that there is a plural event e of my son catching some fish $\mathrm{x}$, and the group of fish $\mathrm{x}$ can be divided into triplets, each of which participated in some subevent of e, the larger catching event. Clearly, these truthconditions will hold in an event-distributive scenario where there are multiple events of my son catching three fish. Moreover, it is also clear that there is no comparable participant-distributive scenario where these truth-conditions hold, simply because the only participant in the plural event of catching besides the fish ' $\mathrm{x}$ ' is the atomic individual 'my son'. 
For similar reasons, our semantics predicts that intransitive sentences containing distributives numerals, such as (39), will only describe event-distributive scenarios.

\section{Intransitive Sentence with a Distributive Numeral}
a. Sentence:
Dáxgaanáx
shaax'wsáani has aawal'éx. two.DIST.HUM girls 3plS.danced
'They danced in twos'.
b. $\quad \underline{L F}: \quad\left[\mathrm{s} \exists \mathrm{e}\left[\mathrm{s}[\right.\right.$ dáxgaanáx shaax’wsáani $]\left[{ }_{v \mathrm{P}} v[\mathrm{vP}\right.$ has aawal'éx $\left.\left.\left.]\right]\right]\right]$
c. $\quad$ Predicted Truth-Conditions

$$
\begin{aligned}
& \exists \mathrm{Ae} . \exists \mathrm{x} .{ }^{*} \operatorname{girl}(\mathrm{x}) \&{ }^{*} \operatorname{danced}(\mathrm{e}) \&{ }^{*} \operatorname{Agent}(\mathrm{e})=\mathrm{x} \& \\
& \quad<\mathrm{e}, \mathrm{x}>=\sigma_{<\mathrm{e}, \mathrm{y}>} \cdot \mathrm{y}<\mathrm{x} \&|\mathrm{y}|=2 \& \mathrm{e}^{\prime}<\mathrm{e} \& \operatorname{Participant}\left(\mathrm{e}^{\prime}, \mathrm{y}\right)
\end{aligned}
$$

As the reader can again confirm, the truth-conditions in (64c) state that there is a plural event e of some girls x dancing, and the group of girls x can be divided up into pairs, each of which participated in some subevent of e. As with (63c), these truth-conditions will hold in an eventdistributive scenario where there are multiple events of two girls dancing. However, given that there is no other participant in the plural event e besides the girls, it is not possible to imagine a participant-distributive scenario where (64c) holds.

Finally, let us consider sentences like (40), which contain multiple distributive numerals. As shown below, such sentences are predicted to have the LF in (65b), and thus the truthconditions in $(65 \mathrm{c})$.

\section{Transitive Sentences with Two Distributive Numerals}

a. Sentence:

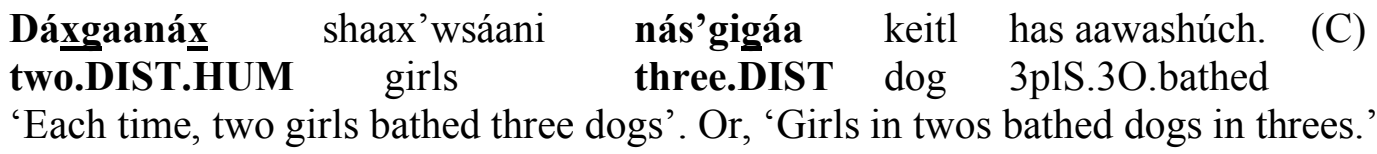

b. $\quad \underline{\mathrm{LF}}: \quad\left[\mathrm{s} \exists \mathrm{e}\left[{ }_{v \mathrm{P}}\right.\right.$ [ dáxgaanáx shaax’wsáani ]

$\left[{ }_{v \mathrm{P}} v \quad[\mathrm{VP}[\right.$ nás'gigáa keitl ] has aawashúch ]...]

c. $\quad$ Predicted Truth-Conditions:

$$
\begin{aligned}
& \exists \text { e . } \exists \mathrm{x} .{ }^{*} \operatorname{girl}(\mathrm{x}) \& \exists \mathrm{z} .{ }^{*} \operatorname{dog}(\mathrm{z}) \& * \text { bathe }(\mathrm{e}) \& * \operatorname{Agent}(\mathrm{e})=\mathrm{x} \& *^{*} \text { Theme }(\mathrm{e})=\mathrm{z} \& \\
& <\mathrm{e}, \mathrm{x}>=\sigma_{<\mathrm{e}}, \mathrm{y}>\mathrm{y}<\mathrm{x} \&|\mathrm{y}|=2 \& \mathrm{e}^{\prime}<\mathrm{e} \& \operatorname{Participant}\left(\mathrm{e}^{\prime}, \mathrm{y}\right) \\
& <\mathrm{e}, \mathrm{z}>=\sigma_{<\mathrm{e}, \mathrm{u}}>\mathrm{u}<\mathrm{z} \&|\mathrm{u}|=3 \& \mathrm{e}^{\prime}<\mathrm{e} \& \operatorname{Participant}\left(\mathrm{e}^{\prime}, \mathrm{u}\right)
\end{aligned}
$$

The predicted truth-conditions in (65c) are rather complex, but basically amount to the following informal statement: (i) there is a plural event e of a group of girls $\mathrm{x}$ (cumulatively) bathing a group of $\operatorname{dogs} z$, and (ii) $x$ can be divided up into pairs, each of which participated in some subevent of e, and (iii) $\mathrm{z}$ can be divided up into triplets, each of which participated in some 
subevent of e. Thus, as the reader can confirm, the truth-conditions in (65c) will hold in a scenario like the one sketched below.

\section{Event-Distributive Scenario Validating (65c)}

\begin{tabular}{cll} 
Bathings & Agent & Theme \\
\hline $\mathrm{e}_{1}$ & Linda+Anne & Sparky+Rex + Spot \\
$\mathrm{e}_{2}$ & Sue+Jen & Fido+Lucky+Lassie \\
$\mathrm{e}_{3}$ & Peggy+Mary & Ruffles + Toto + Sparkles
\end{tabular}

In this scenario, there a plural event $\mathrm{e}_{1}+\mathrm{e}_{2}+\mathrm{e}_{3}$ whose agent is a group of girls (Linda + Anne + Sue + Jen + Peggy + Mary), and whose theme is a group of dogs (Sparky + Rex + Spot + Fido+Lucky+Lassie+Ruffles+Toto+Sparkles). Moreover, it is clear that the group of girls can be divided into pairs, each of which participated in some subevent of $\mathrm{e}_{1}+\mathrm{e}_{2}+\mathrm{e}_{3}$, and that the group of dogs can be divided into triplets, each of which participated in some subevent of $\mathrm{e}_{1}+\mathrm{e}_{2}+\mathrm{e}_{3}$. Thus, the truth-conditions in (65c) indeed hold in this event-distributive scenario. Furthermore, note that those truth-conditions require each subevent of $\mathrm{e}_{1}+\mathrm{e}_{2}+\mathrm{e}_{3}$ to contain a plurality of girls and dogs. Consequently, it is not possible for each such subevent to contain an atomic member of some participant in the larger event $\mathrm{e}_{1}+\mathrm{e}_{2}+\mathrm{e}_{3}$, and so there is no participant-distributive scenario where $(65 \mathrm{c})$ will hold true.

In this way, our semantics is able to predict the key facts in (38)-(40). It is also able to predict certain, more fundamental features of distributive numerals. First, given the lexical entries in (55) and (59), the inability for distributive numerals to modify demonstrative DPs (19) follows from simple type-theoretic considerations. Under the natural assumption that demonstrative DPs are of type $e$, the impossibility of (19b) follows from the fact that adnominal distributive numerals must combine with an expression of type $<e t>$ (59). Similarly, under the assumption that demonstratives are themselves of type $<e t, e>$ the impossibility of (19a) follows from the fact that NPs modified by distributive numerals are of type $<<e, \varepsilon t><\varepsilon t>>$. Finally, as the reader can confirm, the lexical entries in (55) and (59) both entail that the distributive suffix gáa will only affix to numerals, and never to NPs (27b) or other cardinality predicates (27c).

Let us also consider again the very defining properties of distributive numerals.

\section{Distributive Numeral}

A morphosyntactic construction containing a numeral, whereby (i) the sentence as a whole receives a distributive reading, and (ii) under the allowable readings, the numeral contained within the construction must be interpreted as if it is within the scope of a distributive operator.

As we will now see, this range of properties follows directly from our semantics in (55) and (59). First, let us consider the property in (i): sentences with distributive numerals must receive distributive readings. It is easy to see that our semantics predicts the contraposition of this statement: sentences with distributive numerals cannot receive collective or cumulative readings. To see why, consider again the contrast between (28a) and (28b). Importantly, in the collective scenario under (28), there are exactly two dogs that are washed. However, sentence (28b), containing the distributive numeral, will receive the truth-conditions below. 


\section{Truth-Conditions of Sentence (28b)}

$$
\begin{aligned}
& \exists \text { e . } \exists \mathrm{x} . * \operatorname{dog}(\mathrm{x}) \& * \text { bathe(e) \& } * \operatorname{Agent}(\mathrm{e})=\sigma_{\mathrm{y}} *{ }^{*} \operatorname{girl}(\mathrm{y}) \& * \text { Theme }(\mathrm{e})=\mathrm{x} \& \\
& <\mathrm{e}, \mathrm{x}>=\sigma_{<\mathrm{e}, \mathrm{z}>} . \mathrm{z}<\mathrm{x} \&|\mathrm{z}|=2 \& \mathrm{e}^{\prime}<\mathrm{e} \& \operatorname{Participant}\left(\mathrm{e}^{\prime}, \mathrm{z}\right)
\end{aligned}
$$

Note that, according to these truth conditions, there is a plurality $\mathrm{x}$ that contains pairs of dogs $\mathrm{z}$ as proper parts. Consequently, the truth-conditions above will only hold in scenarios that have more than two dogs, and so could not hold in a collective scenario like that in (28).

More generally, one can see that our semantics predicts that any sentence containing the distributive numeral ' $n$-gáa' will only be true in scenarios where there are more than $n$ things satisfying the associated NP. After all, as the reader can confirm, our semantics in (55) and (59) will entail that there is a plurality of NPs $\mathrm{x}$ with multiple proper sub-groups y of cardinality $n$, each of which participate in some subevent e' of a larger event e. Thus, there must be more than $n$ NPs participating in the larger event e. However, a collective or cumulative reading of a sentence containing the plain numeral $n$ will necessarily be true in scenarios containing only $n$ such things. Therefore, it follows that a sentence with a distributive numeral ' $n$-gáa' will not allow for the collective or cumulative readings observed for sentences with the plain numeral $n$.

For exactly these reasons, the second defining property under (67) also follows: a sentence containing the distributive numeral ' $n$-gáa' will be interpreted as if the numeral $n$ falls within the scope of a distributive operator. To begin, note that if a numeral $n$ falls within the scope of a distributive operator - like the numeral two in (34) - then the resulting truthconditions will hold if there are more than $n$ things satisfying the associated NP. In this way, the interpretation yielded by our semantics is akin to one where the numeral modified by gáa falls within the scope of a distributive operator. Moreover, if a numeral $n$ scopes above a distributive operator - like the numeral three in (34) - then the resulting truth-conditions hold if there are exactly $n$ things satisfying the associated NP. For this reason, then, our proposed semantics predicts that distributive numerals will not have an interpretation akin to such wide-scope numerals. Finally, note that although our analysis predicts this core characteristic of distributive numerals, it does not actually make use of the distributive operator in (2), unlike prior accounts (Oh 2001, 2005; Zimmermann 2002). ${ }^{20}$ Consequently, this analysis avoids the key technical challenges surrounding the use of operators like (2) in the analysis of distributive numerals, i.e., (i) the apparent mismatch between the surface location of the numeral and the scope of the distributive operator, and (ii) the need for a type-ambiguity in the operator to obtain both the construals in (4).

To close this section, let us now consider the fact that, like many languages with distributive numerals, obtaining either a distributive or an inverse scope reading in Tlingit requires the presence of such numerals (30), (31), (35). First, it is natural to assume that, like all people, speakers of Tlingit have a strong comprehension bias for 'surface level' parses, and against parses that employ covert DIST operators like (2), or covert movement like QR. Consequently, speakers will be inherently biased against distributive or inverse scope readings of sentences with plain numerals. Furthermore, note that the inclusion of a distributive numeral can

\footnotetext{
${ }^{20}$ It was, of course, for this reason that the definition in (1) was so carefully worded (Footnote 3).
} 
create structures that are true only in the scenarios where the corresponding distributive or inverse scope reading would hold (30), (31), (35). Therefore, if a Tlingit speaker ever wishes to unambiguously express such truth-conditions, a sentence containing an overt distributive numeral is pragmatically preferable to a sentence containing plain numerals. As a result of this pragmatic pressure, speakers will be quite disinclined to interpret sentences with plain numerals as having either distributive or inverse scope readings.

We have seen thus far that our formal semantics in (55) and (59) can account for all the properties observed in Sections 3 and 4 for distributive numerals in Tlingit, as well as several fundamental characteristics of distributive numerals across languages. Furthermore, it successfully avoids the issues surrounding the approaches of Oh (2001, 2005), Zimmermann (2002) and Champollion (2012), without introducing the complex formal machinery of DPIL analyses such as Henderson 2011 and Dotlačil 2012. In Section 6, we will see that this analysis might also offer novel treatments of certain puzzles observed in other languages containing distributive numerals. Before we come to this, however, there a few technical matters relating to the semantics in (55) and (59) that must be addressed.

\subsection{Some Technical Matters: Partitions and Subparts}

In addition to the works mentioned in Footnote 19, the semantics in (55) and (59) also builds upon the work of Balusu (2006) on the distributive numerals of Telugu, particularly his analysis of event-distributive construals in that language. Importantly, Balusu (2006) demonstrates that an analysis along these lines will over-generate, unless one key addition is made. I will illustrate the issue with Tlingit data parallel to the Telugu data discussed by Balusu.

To begin, our semantics in (59) will assign sentence (69a) the truth-conditions in (69b), which state merely that there is an event of 'Girls jumping' that can be divided up into subevents of two girls jumping.

$$
\begin{aligned}
& \begin{array}{lll}
\text { a. Dáxgaa } & \text { shaax’wsáani } \\
\text { two.DIST } & \text { girls }
\end{array} \\
& \text { Girls jumped in twos. } \\
& \text { kei has kawdik'én. } \\
& \text { they.jumped } \\
& <\mathrm{e}, \mathrm{x}>=\sigma_{<\mathrm{e}}, \mathrm{y}>\cdot \mathrm{y}<\mathrm{x} \&|\mathrm{y}|=2 \& \text { e' }<\mathrm{e} \& \operatorname{Participant}\left(\mathrm{e}^{\prime}, \mathrm{y}\right)
\end{aligned}
$$

Balusu (2006) points out that truth-conditions along these lines will be too weak. That is, they will hold in all three of the scenarios in (70) below. However, speakers report that sentence (69a) is only true in scenarios $(70 \mathrm{a}, \mathrm{b})$; it is rejected for scenario $(70 \mathrm{c})$.

\section{(70) Events of Girls Jumping that Can be Divided into Subevents of Two Girls Jumping}

a. $\quad$ Girls Jumping Two at a Time

The girls are playing a funny sort of game. They are standing in a line, and every 10 seconds or so, two girls in the line jump up at the same time.

Judgment: Sentence (69a) is true in this scenario. 
b. Girls Jumping In Groups of Two

The girls are playing a funny sort of game. When we look outside, we see that they have grouped themselves into pairs. Each pair of girls is standing apart from the others, holding hands. The girls all count together in unison "one, two, three". At three, all the girls together jump at the same time.

Judgment: Sentence (69a) is true in this scenario.

\section{c. Girls Paired Only In Terms of Clothing}

The girls are playing a funny sort of game. When we look outside, we see that they are all standing together in a single group. Curiously, though, each is dressed just like some other girl. That is, two girls are both wearing a black dress, two are both wearing a white dress, two are both wearing a striped dress, etc. The girls who are dressed similarly are not necessarily standing anywhere near each other. Finally, the girls all count together in unison "one, two, three". At three, all the girls together jump at the same time.

Judgment: Sentence (69a) is not true in this scenario.

Readers familiar with the semantic literature on distributivity will no doubt have noticed that the basic issue here is one widely discussed throughout that literature: without some 'brakes' on how pluralities can be divided into subgroups, distributive sentences are predicted to have weaker truth-conditions than they appear to have (Lasersohn 1995: 134-141, Schwarzschild 1996: 63-68). The solution proposed by Balusu (2006), which I will also adopt here, is again one that is common in the wider literature on distributivity. In brief, Balusu proposes that the division of the event e into subevents e' must be made relative to a contextually supplied partition, and some such partitions are simply more cognitively natural than others. ${ }^{21}$

To begin, a partition of an event $\mathrm{e}$ is an exhaustive division of e into subevents e', none of which overlap. Stated more formally, let us introduce the notion of a 'partition function', which maps an event e into some partition of e.

\section{(71) Definition of Partition Function}

Let Part be a function from events to sets of events. Part is a 'partition function' if for any event e:

a. $\quad \mathrm{e}=\sigma_{\mathrm{e}^{\prime}} \cdot \mathrm{e}^{\prime} \in \operatorname{Part}(\mathrm{e})$, and

b. For any $\mathrm{e}^{\prime}, \mathrm{e}^{\prime \prime} \in \operatorname{Part}(\mathrm{e})$, there is no $\mathrm{e}^{\prime \prime}$ ' such that $\mathrm{e}^{\prime \prime}, \leq \mathrm{e}$ ' and $\mathrm{e}^{\prime \prime}, \leq \mathrm{e} "$

Condition (71a) states that the function Part maps an event e to a set of events that summed together equal e, while condition (71b) states that Part maps e to a set of events, none of which overlap another. Thus, such a function Part will map events into partitions of those events.

We will now assume that the meaning of a distributive numeral makes reference to some contextually salient, cognitively natural partition function. That is, like distributive operators more generally (Schwarzschild 1996: 63-71), distributive numerals have a context-dependent

\footnotetext{
${ }^{21}$ It should be noted, however, that most of the literature on distributivity makes use of the weaker concept of a 'cover', rather than a 'partition' (Schwarzschild 1996: 64). As we will see in a moment, however, there are some empirical advantages to following Balusu's use of strict partitions, rather than covers.
} 
meaning, and are interpreted relative to some (cognitively natural) partition function Part, as roughly sketched below for adnominal $-g a ́ a .^{22}$

\section{Augmented Semantics for Adnominal Distributive Numerals}

$$
\begin{aligned}
& {\left[\left[\text {-gáa }_{\mathrm{ADN}}\right]\right]^{\text {Part }}=} \\
& \begin{array}{r}
{\left[\lambda \mathrm{n}_{\mathrm{n}}:\left[\lambda \mathrm{Q}_{<\mathrm{et}>}:\left[\lambda \mathrm{P}_{<\mathrm{e}, \mathrm{t}>}:\left[\lambda \mathrm{e}_{\mathrm{e}}: \exists \mathrm{x} . \mathrm{Q}(\mathrm{x}) \& \mathrm{P}(\mathrm{x})(\mathrm{e}) \&\right.\right.\right.\right.} \\
\left.\left.\quad<\mathrm{e}, \mathrm{x}>=\sigma_{<\mathrm{e},}, \mathrm{y}>\cdot \mathrm{y}<\mathrm{x} \&|\mathrm{y}|=\mathrm{n} \& \mathrm{e}^{\prime} \in \operatorname{Part}(\mathrm{e}) \& \operatorname{Participant}\left(\mathrm{e}^{\prime}, \mathrm{y}\right)\right] \ldots\right]
\end{array}
\end{aligned}
$$

The key difference between (72) and (59) is that in the former, the pair $<\mathrm{e}, \mathrm{x}>$ must be divisible into pairs $<\mathrm{e}^{\prime}, \mathrm{y}>$ where (crucially) e' is a member of the partition that Part yields for e. Thus, (72) places a more stringent condition on the pairs $<\mathrm{e}$ ', $\mathrm{y}>$ making up $<\mathrm{e}, \mathrm{x}>$ than is found in (59). To illustrate, sentence (69a) is now mapped to the truth-conditions in (73).

\section{Truth Conditions that (72) Predicts for Sentence (69a)}

$$
\begin{aligned}
& \exists \text { ヨ. } \exists \text { x } .{ }^{*} \operatorname{girl}(\mathrm{x}) \& * \text { jump(e) \& } * \operatorname{Agent}(\mathrm{e})=\mathrm{x} \& \\
& <\mathrm{e}, \mathrm{x}>=\sigma_{<\mathrm{e}^{\prime}, \mathrm{y}>} \cdot \mathrm{y}<\mathrm{x} \&|\mathrm{y}|=2 \& \mathrm{e}^{\prime} \in \operatorname{Part}(\mathrm{e}) \& \operatorname{Participant}\left(\mathrm{e}^{\prime}, \mathrm{y}\right)
\end{aligned}
$$

Consequently, our semantics in (72) now predicts that (69a) can be interpreted as true only if there is some contextually salient, cognitively natural partition function Part which maps an event e of girls jumping to (non-overlapping) subevents e' of two girls jumping. Following Balusu (2006), we can now understand the data in (70) in the following terms. First, in scenario (70a), the function Part must map the event e to subevents e' which are distinguished in terms of their time. Similarly, in (70b), Part must map e to subevents that are distinguished in terms of their location. It is not implausible to suppose that such partitions are rather cognitively natural, and so also generally contextually salient. In scenario (70c), however, the subevents of e that contain two girls jumping are neither temporally nor spatially distinguishable. Instead, these subevents are distinguished in terms of the style of clothes worn by participants in the event. It's not implausible to suppose that such a partition - though logically possible - is neither cognitively natural nor contextually salient. Consequently, there is no (cognitively/contextually available) function Part that will allow the truth-conditions in (73) to hold in scenario (70c), and so sentence (69a) will be rejected for this scenario. ${ }^{23}$

In addition to accounting for the contrasts in (70), our augmentation in (72) also resolves another, related problem for the semantics in (59), noted by an anonymous reviewer for Language. First, consider the scenario in (74) below, where my daughter bathes three dogs, one at a time.

\footnotetext{
${ }^{22}$ Adverbial -gáa will require parallel changes in its denotation.

${ }^{23}$ Again, readers familiar with the broader literature on distributivity will see clear parallels to analyses making use of 'covers' in the semantics of DIST (Schwarzschild 1996: 92-98, 123-131).
} 


\begin{tabular}{ccc} 
Individual Bathings & Agent & Theme \\
\hline $\mathrm{e}_{1}$ & Hazel & Sparky \\
$\mathrm{e}_{2}$ & Hazel & Spot \\
$\mathrm{e}_{3}$ & Hazel & Rex
\end{tabular}

As noted by the reviewer, in this scenario there is an event of my daughter bathing dogs $\mathrm{e}_{1}+\mathrm{e}_{2}+\mathrm{e}_{3}$ - which can be divided up into subevents of my daughters bathing two dogs. After all, $\mathrm{e}_{1}+\mathrm{e}_{2}+\mathrm{e}_{3}$ is made up of the subevents $\mathrm{e}_{1}+\mathrm{e}_{2}$ and $\mathrm{e}_{2}+\mathrm{e}_{3}$. Consequently, the truth-conditions in (75b) below will hold in scenario (74). Finally, since our semantics in (59) assigns those truthconditions to sentence (75a), our account predicts that (75a) should be true in scenario (74). Although I have not actually yet tested this prediction with speakers, I concur with the reviewer's suspicion that it is false.

\section{(75) Semantic Predictions of (59)}
a.
Ax $\quad$ sée
dáxgaa
keitl aawashúch. ${ }^{24}$
my daughter
two.DIST
dog 3sgS.3O.bathed
'My daughter bathed dogs in twos / two at a time.'
b. $\quad \exists$ e. $\exists \mathrm{x} . * \operatorname{dog}(\mathrm{x}) \& *$ bathe(e) \& $*$ Agent(e) $=$ my.daughter $\& *$ Theme(e) $=\mathrm{x} \&$ $<\mathrm{e}, \mathrm{x}>=\sigma_{<\mathrm{e}, \mathrm{z}>} . \mathrm{z}<\mathrm{x} \&|\mathrm{z}|=2 \& \mathrm{e}^{\prime}<\mathrm{e} \& \operatorname{Participant}\left(\mathrm{e}^{\prime}, \mathrm{z}\right)$

Fortunately, however, our augmented semantics in (72) is able to avoid this (possibly) problematic prediction. Note that (72) requires the subevents e', e', making up e to be members of a partition of e. Consequently, e' and e'" cannot overlap. In scenario (74), however, all the events of bathing two dogs overlap (e.g. $\mathrm{e}_{1}+\mathrm{e}_{2}$ and $\mathrm{e}_{2}+\mathrm{e}_{3}$ ). Therefore, there is not in (74) a partition of $\mathrm{e}_{1}+\mathrm{e}_{2}+\mathrm{e}_{3}$ containing events of bathing two dogs. As the reader can confirm, it thus follows that our semantics in (72) will predict (75a) to be false in scenario (74), which I suspect is the case. $^{25}$

In summary, several empirical problems for our semantics can be circumvented by tying the denotation of the distributive numeral suffix -gáa to a contextually salient partition function. Having shown the need for this addition, I will nevertheless suppress it in the following sections, employing the simpler (but less accurate) semantics in (55) and (59). Before we leave this

\footnotetext{
${ }^{24}$ I have not yet confirmed the well-formedness of this sentence with speakers. However, given its parallels to (38), I am confident that it is well-formed.

25 Given this line of explanation, one might well wonder about a scenario akin to (74), but where there are four events of my daughter bathing a (single) dog. As the reader can confirm, even our semantics in (72) predicts (75a) to be true in such a scenario. For such scenarios, however, I suspect that this is indeed an accurate prediction. Suppose, for example, that bathings $\mathrm{e}_{1}$ and $\mathrm{e}_{2}$ are close together in time, as are bathings $\mathrm{e}_{3}$ and $\mathrm{e}_{4}$, while bathings $\mathrm{e}_{2}$ and $\mathrm{e}_{3}$ are quite separated in time. I strongly suspect - but have not confirmed - that (75a) would be true in such a scenario. Given the temporal separation between $e_{2}$ and $e_{3}$, there would be a contextually salient partition function that would map $\mathrm{e}_{1}+\mathrm{e}_{2}+\mathrm{e}_{3}+\mathrm{e}_{4}$ to the partition $\left\{\mathrm{e}_{1}+\mathrm{e}_{2}, \mathrm{e}_{3}+\mathrm{e}_{4}\right\}$, and so our predicted truth-conditions would hold. Finally, without the temporal separation of $\mathrm{e}_{2}$ and $\mathrm{e}_{3}$, we might suppose that such a partition function would no longer be cognitively natural, and so (75a) would again come out false. To repeat, I have not tested any of this with speakers, but I do strongly suspect that these predictions are accurate, and I invite the reader to share that suspicion.
} 
section, however, a few additional technical remarks are in order regarding the nature of the (proper) sub-part relation ' $<$ ' appealed to in (55), (59) and (72). First, it should be noted that, following Link (1983), this relation holds only between a plurality and the individual entities constituting the plurality. Crucially, this relation does not hold between an individual and its material parts (Link 1983). After all, as noted by a reviewer for Language, our semantics in both (59) and (72) would otherwise wrongly predict that (75a) could be true in a scenario where my daughter bathed a single dog, but did so by washing two of its body parts at a time (e.g., the left legs, then the right legs, then the ears, etc.).

Of course, this remark itself raises the question of what renders a particular collection of matter an 'individual' rather than a 'plurality'; for example, why should a particular dog count as an atomic entity rather than as a plurality of dog-parts? This is an extremely difficult, foundational question in the semantics of plurals, and any attempt to tackle it seriously would take us too far afield. I would, however, like to quote at length a passage from Kratzer (2008), since it relates to one final matter worth discussing:

"Any serious semantics relies on domains for the basic entities that provide the building blocks for the whole repertoire of denotations... For the domains of individuals and events, the subdomains containing the atoms play a special role... Among the atoms in the domain of individuals are the cups in my cupboard, for example. Those cups have parts, of course, and sometimes we want to quantify over those parts too. Sometimes. Usually, we do not recognize the parts of a cup as separate individuals... The parts of an event behave no differently. True, the individuation conditions for events are a bit looser than those of most individuals, but that doesn't mean that anything goes. We can't assume that weirdness of parts should not play a role for events at all." (Kratzer 2008, emphasis added).

Again, space precludes a full summary of the context for these remarks, but in brief, these comments by Kratzer are in reference to the intuitive falsity of sentence (76b) in scenario (76a), a fact first discussed by Winter (2000).

(76) a. Scenario: Dave and Bill together are holding wheel A. At the same time, Bill and Tom together are holding wheel B.

b. Sentence: The boys are (each) holding a wheel.

As Kratzer (2008) notes, it is possible for the analyst to 'carve up' the scenario in (76a) into subparts, one where Dave is holding wheel A, one where Bill is holding wheel A, one where Bill is holding wheel B, and one where Tom is holding wheel B. However, this needn't entail that sentence (76b) should be construed by speakers as true in this scenario. After all, the division in question seems rather unnatural, and so the subparts in question are not likely to be recognized by speakers as separate events in the domain of events.

The reason for my mentioning Kratzer's (2008) discussion is that a reviewer raises a very similar issue for our semantics in (59). To begin, consider a scenario where my daughter bathes four dogs all at the same time. That is, she has Sparky, Spot, Rex and Fido all in the tub at the same time, and she washes a bit of Sparky, then a bit of Spot, then a bit of Rex, then a bit of Fido, on and on like that until they all get clean. Following our assumptions from Section 5.1, 
we'd want to say that in this scenario, there is a single event of bathing e, whose agent is my daughter and whose theme is Sparky+Spot+Rex+Fido. Furthermore, it is quite likely that speakers of Tlingit would reject sentence (75a) in this scenario (though I haven't yet tested this). However, as the reviewer points out, it seems that we can carve up the event e into subevents e', where two dogs participate. For example, consider summing together a subevent of washing Sparky for a bit and an event of washing Rex for a bit. Consequently, it seems that our semantics in (59) - and even that in (72) - might wrongly predict (75a) to be true in this scenario of collective bathing.

There are, though, two imaginable responses to this challenge. The first is simply to posit, following our discussion of (70c), that such a partition of this event e into such subevents e' is not cognitively natural (nor contextually salient), and so the truth-conditions predicted by our augmented semantics in (72) will fail to hold. However, we might also imagine a stronger response, akin to that of Kratzer's (2008) treatment of the facts in (76). That is, although we as analysts can 'carve up' such events of collective dog bathing into pieces where two dogs participate, such 'carvings up' do seem as unnatural as the one required to get (76b) true in scenario (76a). Consequently, there may simply be no subevents of such collective dog bathings where two dogs participate. If this is indeed the case, then even our semantics in (59) will continue to make the correct predictions for such scenarios.

Finally, we should also note that - whether or not the reader finds any of these proposed solutions entirely adequate - the issues discussed in this section are by no means peculiar to the analyses proposed in (55), (59) and (72). Rather, these are specific instances of much more general and foundational problems in the theory of plurality and event semantics.

\section{Consequences for Distributive Numerals in Other Languages}

It has often been reported that distributive numerals and other 'distance distributives' appear to be subject to certain locality conditions. For example, Choe (1987) and Oh $(2001,2005)$ observe that Korean sentences like (77a), which contain a distributive numeral inside a subordinate clause, do not admit of a reading akin to (77b), and so cannot describe a scenario like (77c).

\section{(77) Locality Conditions on Distributive Numerals (Choe 1987, Oh 2005)}
a. Chemwentuli [aituli phwungsen-hana-ssik-ul saessta ] malhaessta store.clerks children balloon-one-DIST-ACC bought said 'The store clerks said that the children bought one balloon each / each time.'

b. $\quad \forall \mathrm{x} . \mathrm{x} \leq$ the.store.clerks \& atom( $\mathrm{x}) \rightarrow$

$\mathrm{x}$ said that $\exists y$. one.ballon(y) \& the.kids bought $\mathrm{y}$

'Each of the store clerks said that the children bought one balloon.'

c.

$\begin{array}{clc}\text { Sayings } & \text { Agent } & \text { Proposition Said } \\ e_{1} & \text { clerk }_{1} & \text { 'The kids bought one balloon' } \\ e_{2} & \text { clerk }_{2} & \text { 'The kids bought one balloon' } \\ e_{3} & \text { clerk }_{3} & \text { 'The kids bought one balloon' }\end{array}$


Note that in order to obtain such a meaning, the distributive numeral would need to be interpreted as if it scoped below a distributive operator sitting within the matrix clause. In other words, under the impossible reading in $(77 \mathrm{~b})$, the understood restrictor of the distributive operator is separated from the distributive numeral by a clause boundary. Put even more informally, the data in (77) show that in Korean, an NP marked by a distributive numeral can only 'distributive over' a clausemate. Zimmermann (2002) reports similar facts for parallel sentences in German.

This set of facts follows directly from our analysis in Section 5.2, if we assume that the Korean distributive suffix $-s s i k$ has the semantics of adnominal -gáa in (59). To begin, our account would assign to sentence (77a) the LF in (78a), and so would derive the truth-conditions (roughly) in (78b). ${ }^{26}$

\section{Predicted Structure and Meaning for (77a)}

a. $\quad[\mathrm{S} 1 \quad[v \mathrm{P} 1$ chemwentuli $[v \mathrm{P} 1 \quad v[\mathrm{vP} 1$

[s2 $\exists$ e [vP2 aituli [ ${ }_{\text {PP2}} v$ [vP2 [ phwungsen hana-ssik ] saessta ]...] malhaessta ] ... ]

b. $\quad$ said ( $\sigma_{\mathrm{z}} \cdot{ }^{*}$ store. $\operatorname{clerk}(\mathrm{z})$,

$\exists$ e . $\exists x . * \operatorname{ballon}(\mathrm{x}) \& * \operatorname{buy}(\mathrm{e}) \& * \operatorname{Agent}(\mathrm{e})=\sigma_{\mathrm{y}} * \operatorname{kid}(\mathrm{y}) \& * \operatorname{Theme}(\mathrm{e})=\mathrm{x}$

$\left.\&<\mathrm{e}, \mathrm{x}>=\sigma_{<\mathrm{e}, \mathrm{u}>} . \mathrm{u}<\mathrm{x} \&|\mathrm{u}|=1 \& \mathrm{e}^{\prime}<\mathrm{e} \& \operatorname{Participant}\left(\mathrm{e}^{\prime}, \mathrm{u}\right)\right)$

The store clerks said that

there is an event $e$ of the kids buying some balloons $x$ and

$x$ is the sum of the individuals $y$ that participated in some subevent of $e$

Thus, the LF in (78a) will be assigned a meaning where the distributive numeral hanassik 'one.DIST' scopes within the subordinate clause. The resulting truth-conditions will hold in either of the following scenarios: (i) the store clerks said that the kids (together) several times bought one balloon, or (ii) the store clerks said that each kid bought a balloon. Note, however, that these truth-conditions will not hold in the scenario in $(77 \mathrm{c})$, where each store clerk says that the kids bought (just) one balloon.

One might wonder, however, whether (77c) could be described by an LF where the NP phwungsen hanassik'one.DIST balloon' undergoes QR into the matrix clause, as in (79) below.

\section{Impossible LF for (77a)}

[S1 [ phwungsen hana-ssik ] [ $\mathrm{S} 11$ [ chemwentuli [ ${ }_{v \mathrm{P} 1} v[\mathrm{vP} 1$ $\left[\mathrm{s} 2\right.$ ヨe $\left[{ }_{\nu \mathrm{P} 2}\right.$ aituli $\left[{ }_{\mathrm{vP} 2} v\left[\mathrm{vP} 2_{1} t_{1}\right.\right.$ saessta $\left.] \ldots\right]$ malhaessta $\left.] \ldots\right]$

Note, though, that the QR assumed in (79) would violate the general condition that QR is clause bound (May 1985, 1988). Furthermore, as the reader can confirm, the truth-conditions assigned to (79) would still fail to hold in (77c). Such an LF would necessarily be assigned a 'transparent' or 'de re' reading, where there is a specific group of balloons $\mathrm{x}$ such that the store clerks said that

\footnotetext{
${ }^{26}$ The truth-conditions in (78b) obviously abstract away from the more complex intensional semantics of 'say'.
} 
the kids bought $\mathrm{x}$, a condition that does not hold in scenario $(77 \mathrm{c})$ or fit the reading sketched in (77b). In summary, then, we find that our semantics correctly predicts that (77a) will not allow for a 'non-local' reading akin to $(77 b, c)$.

Our semantics also predicts a fascinating interaction between pluractional morphology and distributive numerals in the Mayan language Kaqchikel. As first observed by Henderson (2011), distributive numerals in Kaqchikel appear to have the exceptional ability to scope below pluractional verbal suffixes. First, consider sentences like (80a), where an NP marked by a plain numeral is argument to a verb bearing the pluractional suffix. Speakers report that such sentences are only true if the same book is searched for multiple times.

\section{Distributive Numerals, Pluractional Morphology, and Scope in Kaqchikel}
a.
$\begin{array}{lll}\text { Xinkanala' } & \text { jun } & \text { wuj } \\ 1 \text { sgS.searched.PA } & \text { one } & \text { book }\end{array}$
'I looked for a book (various times)'
(Henderson 2011)
Speaker Judgment: True only if I looked for the same book multiple times.
b. Xinkanala' ju-jun wuj
1sgS.searched.PA one.DIST book
'I looked for books (various times).' (Henderson 2011)
Speaker Judgment: True only if I looked for a different book each time.

This contrasts strikingly with a sentence like (80b), which differs only in that the NP is modified by a distributive numeral. Unlike (80a), speakers report that (80b) is only true if a different book is searched for each time. Thus, with the plain numeral $(80 \mathrm{a})$, there is one book for every event of searching, whereas with the distributive numeral (80b), each event of searching involves a different book. In this sense, it seems that the numeral in (80a) must 'scope above' the pluractional suffix, while in $(80 \mathrm{~b})$ it must scope below.

Henderson (2011) puts forth a detailed analysis of these and related facts in Kaqchikel, one making use of the 'DPIL' framework (Section 1). According to this analysis, distributive numerals in sentences like (80b) do not truly 'scope below' the pluractional affix, or differ at all in their scope from plain numerals in sentences like (80a). Rather, the semantics of the pluractional affix and the distributive numeral simply interact to produce the effect in question. While space precludes a detailed discussion of Henderson's account, it is worth noting that our semantics in (55) and (59) provides a similar explanation for the facts in (80), without making recourse to the special assumptions and complex formal machinery of the DPIL framework.

Following Lasersohn (1995) and much subsequent work, I will assume the following semantics for pluractional morphology.

\section{(81) Lasersohnian Analysis of Pluractional Morphology (Lasersohn 1995)}

$$
\begin{aligned}
& {[[\mathrm{PA}]]=} \\
& {\left[\lambda \mathrm{P}_{<_{\mathrm{t}}>}:\left[\lambda \mathrm{e}:|\mathrm{e}|>\mathrm{n} . \forall \mathrm{e}^{\prime} . \mathrm{e}^{\prime} \leq \mathrm{e} \& \text { atom }\left(\mathrm{e}^{\prime}\right) \rightarrow \mathrm{P}\left(\mathrm{e}^{\prime}\right)\right.\right.} \\
& \left.\& \forall \mathrm{e}^{\prime}, \mathrm{e}^{\prime \prime} . \mathrm{e}^{\prime}, \mathrm{e}^{\prime \prime} \leq \mathrm{e} \& \operatorname{atom}\left(\mathrm{e}^{\prime}\right) \& \operatorname{atom}\left(\mathrm{e}^{\prime \prime}\right) \rightarrow \neg \tau\left(\mathrm{e}^{\prime}\right)^{\circ} \tau\left(\mathrm{e}^{\prime \prime}\right) \quad\right]
\end{aligned}
$$


According to this semantics, a pluractional affix takes a predicate of events $\mathrm{P}$ as argument, and returns a predicate of events that (i) is restricted to plural events ( $|\mathrm{e}|>n$ ), and (ii) is true of an event $\mathrm{e}$ iff $\mathrm{e}$ is composed of many atomic events that satisfy $\mathrm{P}$ and do not overlap in their time.

Of course, this semantics in (81) assumes that, contrary to what's stated in (44), lexical verbs are pure predicates of events, as sketched in (82a) below. Consequently, the internal arguments of verbs must also be introduced via special syntactic heads akin to little- $v$. For our discussion here, I will assume the head in $(82 \mathrm{~b}) .^{27}$

\section{Slight Changes to Background Semantic Assumptions}
a. $\quad$ Verbs are Predicates of Events:
$[[\operatorname{search}]]=\left[\lambda \mathrm{e}: *^{*} \operatorname{search}(\mathrm{e})\right]$
b. Head Introducing Theme:
$[[\mathrm{Th}]]=[\lambda \mathrm{x}: \lambda \mathrm{e}: * \operatorname{Theme}(\mathrm{e})=\mathrm{x}]$

With these semantic assumptions in place, the plain numeral sentence in (80a) will receive the LF in (83a), and thus the truth-conditions in (83b).

\section{Truth-Conditions Derived for Sentence (80a)}

a. LF-Structure:

$\left[\mathrm{s} \exists \mathrm{e}\left[\mathrm{s}[\right.\right.$ jun wuj $]\left[\mathrm{s} 1\left[{ }_{v \mathrm{P}}\right.\right.$ pro $_{1 \mathrm{sg}}\left[{ }_{v \mathrm{P}} v\left[\mathrm{vP}[\mathrm{v}\right.\right.$ xinkan PA $]\left[\mathrm{ThP}\right.$ Th $\left.\left.t_{1}\right] \ldots\right]$

b. $\quad$ Truth-Conditions

$$
\begin{aligned}
& \exists \text { e } . \exists x \cdot{ }^{*} \operatorname{book}(x) \&|x|=1 \& * \operatorname{Agent}(e)=\text { speaker } \& * \text { Theme }(e)=x \& \\
& \left.|\mathrm{e}|>\mathrm{n} \& \forall \mathrm{e}^{\prime} \leq \mathrm{e} \& \text { atom( } \mathrm{e}^{\prime}\right) \rightarrow *^{*} \operatorname{search}\left(\mathrm{e}^{\prime}\right) \& \\
& \forall \mathrm{e}^{\prime}, \mathrm{e}^{\prime \prime} . \mathrm{e}^{\prime}, \mathrm{e}^{\prime \prime} \leq \mathrm{e} \& \text { atom(e') } \& \text { atom(e'’) } \rightarrow \neg \tau\left(\mathrm{e}^{\prime}\right)^{\circ} \tau\left(\mathrm{e}^{\prime \prime}\right)
\end{aligned}
$$

There is a (plural) event e, whose agent is the speaker, and whose theme is a book $x$, and e is composed of many atomic events e' of searching,

and these atomic events of searching do not overlap in their time.

The truth-conditions in (83b) state that there is a plurality of searching events e whose cumulative theme is a single book x. It follows, then, that this book x must also be the theme of the individual searching events contained in e. Therefore, we correctly predict that (80a) will only be true if the same book is searched for multiple times.

Now let us consider the distributive numeral sentence in (80b). Given our assumptions above, it will receive the LF structure in (84a) and so the truth-conditions in (84b).

\section{Truth-Conditions Derived for Sentence (80b)}

a. LF-Structure:

$\left[\mathrm{s} \exists \mathrm{e}\left[{ }_{\mathrm{P}}\right.\right.$ pro $_{1 \mathrm{sg}}\left[{ }_{\mathrm{vP}} v[\mathrm{vP}[\mathrm{v}\right.$ xinkan PA $][\mathrm{ThP}$ Th [jun-DIST wuj ] ] ... ]

\footnotetext{
27 The reader is invited to confirm that these changes in no way impact the results from Section 5.
} 


\section{b. Truth-Conditions}

$$
\begin{aligned}
& \exists \mathrm{J} . \exists \mathrm{x} . * \operatorname{book}(\mathrm{x}) \& * \operatorname{Ag}(\mathrm{e})=\text { speaker } \& * \operatorname{Thm}(\mathrm{e})=\mathrm{x} \& \\
& |\mathrm{e}|>\mathrm{n} \& \forall \mathrm{e}^{\prime} \leq \mathrm{e} \& \text { atom( }\left(\mathrm{e}^{\prime}\right) \rightarrow *^{*} \operatorname{search}\left(\mathrm{e}^{\prime}\right) \\
& \& \forall \mathrm{e}^{\prime}, \mathrm{e}^{\prime \prime} . \mathrm{e}^{\prime}, \mathrm{e} " \leq \mathrm{e} \& \text { atom(e') \& atom(e") } \rightarrow \neg \tau\left(\mathrm{e}^{\prime}\right){ }^{\circ} \tau\left(\mathrm{e}^{\prime \prime}\right) \\
& \&<e, x>=\sigma_{<e^{\prime}, y>} \cdot y<x \&|y|=1 \& e^{\prime}<e \& \text { Participant }\left(e^{\prime}, y\right)
\end{aligned}
$$

There is a (plural) event e, whose agent is the speaker, and whose theme is a group of books $x$, and e is composed of many atomic events e' of searching, and these atomic events of searching do not overlap in their time, and $x$ is the sum of all the individuals $y$ that participate in a subevent of $e$

As the informal paraphrase in (84b) indicates, the predicted truth-conditions will hold if there is a plurality of searching events e, whose cumulative theme is a group of books $\mathrm{x}$, and $\mathrm{x}$ can be divided up into individuals, each of which is theme to some subevent of e. Therefore, these truthconditions will hold in a scenario like (85a), where many different books are searched for.

\section{Scenarios Verifying and Falsifying (80b)}

a. $\quad$ Verifying Scenario

b. $\quad$ Not a Verifying Scenario
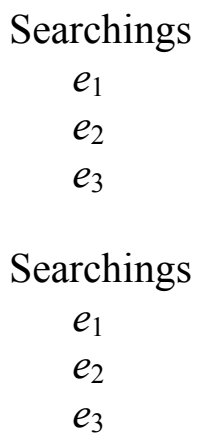

$\begin{array}{ll}\text { Agent } & \text { Theme } \\ \text { speaker } & \text { book }_{1} \\ \text { speaker } & \text { book }_{2} \\ \text { speaker } & \text { book }_{3}\end{array}$

Agent Theme speaker $\quad$ book $_{1}$ speaker $\quad$ book $_{1}$ speaker $\quad$ book $_{1}$

Furthermore, these truth-conditions will not hold in a scenario like (85b), where the same book is searched for multiple times. The issue is that the cumulative theme $x$ of $e_{1}+e_{2}+e_{3}$ is just the individual book ${ }_{1}$. Therefore, since book ${ }_{1}$ is an atom, there is no y such that $\mathrm{y}<\operatorname{book}_{1} \&|\mathrm{y}|=1$, and so the condition ' $<\mathrm{e}, \mathrm{x}>=\sigma_{<\mathrm{e}}, \mathrm{y}>\cdot \mathrm{y}<\mathrm{x} \&|\mathrm{y}|=1 \& \mathrm{e}^{\prime}<\mathrm{e} \&$ Participant(e',y)' in (84b) will fail to hold in (85b).

Taking these results together, we find that our semantics in $(55) /(59)$ can derive the intriguing pattern in (80) from a Lasersohnian treatment of pluractionals (81)-(82). Furthermore, as in the work of Henderson (2011), we do not actually view the distributive numeral in (80b) as 'scoping below' the pluractional morphology. Rather, as the LFs and truth-conditions in (83)(84) make clear, our account treats both the plain numeral and the distributive numeral in (80) as scoping above the pluractional affix. However, the meaning of the distributive numeral ju-jun 'one.DIST' in (80b) independently serves to distribute 'one book' to each subevent of the larger plural event. Consequently, each such subevent will have a distinct book as its theme, which is akin to the numeral scoping below the pluractional.

We have thus seen that the analysis of Tlingit distributive numerals in Section 5 offers viable, novel analyses of distributive numerals in other languages as well. In the following section, we will see that this analysis might also advance our understanding of the broader 
category of 'distance distributivity', in that it could offer a novel approach to English's binominal each construction.

\section{A Possible Extension to 'Binominal Each' in English}

The term 'binominal each' refers to the construction in (86a), where the distributive marker each is appended post-nominally to an NP modified by a numeral (Safir \& Stowell 1988, Zimmermann 2002, Champollion 2012, Dotlačil 2012).

\section{Binominal Each in English}

a. Illustrative Sentence: $\quad$ My sons caught [ three fish each ].

b. $\quad$ Apparent Truth-Conditions:

$\forall \mathrm{x} . \mathrm{x} \leq \mathrm{my}$. sons $\&$ atom(x) $\rightarrow \exists \mathrm{y}$. three.fish(y) \& $\mathrm{x}$ caught $\mathrm{y}$

Each of my sons caught three fish.

As has long been observed (Gil 1982), English binominal each seems to have all the defining properties of a distributive numeral construction (1). After all, sentences like (86a) only allow for distributive readings, ones in which the numeral participating in the construction scopes below a distributive operator (86b). However, as has also long been observed (Gil 1982), English binominal each differs in one key way from canonical distributive numeral constructions. As shown below, binominal each sentences can only describe participant-distributive scenarios (87a); in event-distributive scenarios like (87b), such sentences are judged to be false.

\begin{tabular}{|c|c|c|c|}
\hline$\underline{\text { Verifying Scenario for }(86 a)}$ & $\begin{array}{l}\text { Catchings } \\
\mathrm{e}_{1} \\
\mathrm{e}_{2}\end{array}$ & $\begin{array}{l}\text { Agent } \\
\text { Tom } \\
\text { Bill }\end{array}$ & $\begin{array}{l}\text { Theme } \\
\text { fish }_{1}+\text { fish }_{2}+\text { fish }_{3} \\
\text { fish }_{4}+\text { fish }_{5}+\text { fish }_{6}\end{array}$ \\
\hline Not a Verifying Scenario: & $\begin{array}{l}\text { Catchings } \\
\qquad \begin{array}{l}\mathrm{e}_{1} \\
\mathrm{e}_{2} \\
\mathrm{e}_{3}\end{array}\end{array}$ & $\begin{array}{c}\text { Agent } \\
\text { Tom+Bill } \\
\text { Tom+Bill } \\
\text { Tom+Bill }\end{array}$ & $\begin{array}{l}\text { Theme } \\
\text { fish }_{1}+\text { fish }_{2}+\text { fish }_{3} \\
\text { fish }_{4}+\text { fish }_{5}+\text { fish }_{6} \\
\text { fish }_{7}+\text { fish }_{8}+\text { fish }_{9}\end{array}$ \\
\hline
\end{tabular}

Ideally, an analysis of canonical distributive numerals, such as those found in Tlingit, should offer some perspective upon the semantics of English binominal each, as well as an explanation for the key difference between the two constructions. Let us therefore consider how our semantics in $(55) /(59)$ might be augmented to apply to English sentences like (86a).

First, following prior authors (Zimmermann 2002, Champollion 2012, Dotlačil 2012), I will assume that the binominal each construction contains a null pronoun, which must be bound by some higher argument within the clause (Section 1). That is, the phrase 'three fish each' will be assumed to have the structure below. 
Key Morpho-Syntactic Assumption ${ }^{28}$

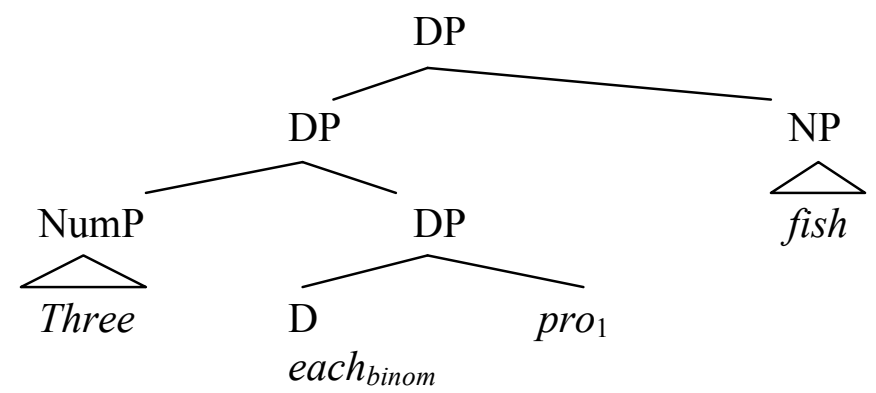

Next, let us assume that the 'each' of the binominal each construction has the semantics in (89b), which makes use of the ternary sum operator in (89a) (cf. (43b), (53)).

\section{The Semantics of Binominal Each}

a. $\quad$ Ternary Sum Operator

(i) Triple Addition:

$<\mathrm{x}_{1}, \mathrm{x}_{2}, \mathrm{x}_{3}>+<\mathrm{y}_{1}, \mathrm{y}_{2}, \mathrm{y}_{3}>==_{\mathrm{df}} \quad<\mathrm{x}_{1}+\mathrm{y}_{1}, \mathrm{x}_{2}+\mathrm{y}_{2}, \mathrm{x}_{3}+\mathrm{y}_{3}>$

(ii) Ternary Sum Operator:

$\sigma_{<\mathrm{x}, \mathrm{y}, \mathrm{z}>} \cdot \mathrm{Q}(\mathrm{x})(\mathrm{y})(\mathrm{z}) \quad=_{\mathrm{df}}$

the triple $<\alpha, \beta, \gamma>$ such that $<\alpha, \beta, \gamma>\in *\{<\mathrm{x}, \mathrm{y}, \mathrm{z}>\mathrm{Q}: \mathrm{Q}(\mathrm{x})(\mathrm{y})(\mathrm{z})\}$, and if $<\delta, \zeta, \psi>\in *\{<\mathrm{x}, \mathrm{y}, \mathrm{z}>: \mathrm{Q}(\mathrm{x})(\mathrm{y})(\mathrm{z})\}$, then $\delta \leq \alpha$, and $\zeta \leq \beta$, and $\psi \leq \gamma$

b. $\quad$ Semantics for Binominal Each

$$
\begin{array}{r}
{\left[\left[\operatorname{each}_{\text {binom }}\right]\right]=\left[\lambda \mathrm{z}_{\mathrm{e}}:\left[\lambda \mathrm{n}_{\mathrm{n}}:\left[\lambda \mathrm{Q}_{<\mathrm{et}>}:\left[\lambda \mathrm{P}_{<\mathrm{e}, \mathrm{t}>}:\left[\lambda \mathrm{e}_{\mathrm{t}}: \exists \mathrm{x} . \mathrm{Q}(\mathrm{x}) \& \mathrm{P}(\mathrm{x})(\mathrm{e}) \&\right.\right.\right.\right.\right.} \\
<\mathrm{e}, \mathrm{x}, \mathrm{z}>=\sigma_{<\mathrm{e}}, \mathrm{y}, \mathrm{s}>\cdot \mathrm{y}<\mathrm{x} \&|\mathrm{y}|=\mathrm{n} \& \mathrm{~s}<\mathrm{z} \&|\mathrm{~s}|=1 \& \\
\text { e' } \left.\left.<\mathrm{e} \& \operatorname{Participant}\left(\mathrm{e}^{\prime}, \mathrm{y}\right) \& \operatorname{Participant}\left(\mathrm{e}^{\prime}, \mathrm{s}\right)\right] \ldots\right]
\end{array}
$$

Note that the lexical entry in (89) is rather close to that given in (59) for adnominal -gáa in

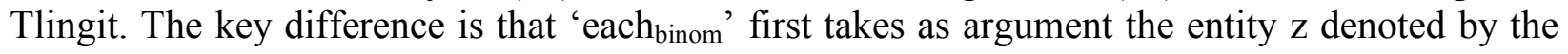
null pronoun. Furthermore, having taken this entity $\mathrm{z}$ as argument, 'each ${ }_{\text {binom' }}$ adds the condition that the event e can be divided into subevents e' each of which contain $n$ things satisfying the modified NP, and a single atomic subpart of the entity $z$. To see the effect of this condition in greater detail, let us examine the meaning we derive for sentence (86a).

\section{Predicted Truth-Conditions for Sentence (86a)}

a. $\quad \underline{\mathrm{LF}}: \quad\left[\mathrm{s} \exists \mathrm{e}\left[{ }_{\nu \mathrm{P}}[\mathrm{my}\right.\right.$ sons $]\left[{ }_{\nu \mathrm{P}} 1\left[{ }_{\nu \mathrm{P}} t_{1}\left[{ }_{\nu \mathrm{P}} v\right.\right.\right.$ [vp caught $\left[\right.$ three fish each pro $\left.\left._{1}\right] \ldots\right]$

${ }^{28}$ I will remain agnostic as to how the surface order 'three fish each' is to be derived from this structure. 


\section{b. $\quad$ Predicted Truth-Conditions}

$$
\begin{aligned}
& \text { ヨe . } \exists \text { x. } * \text { fish }(\mathrm{x}) \& * \operatorname{catch}(\mathrm{e}) \& * \text { Agent }(\mathrm{e})=\text { my.sons \& } * \text { Theme }(\mathrm{e})=\mathrm{x} \& \\
& <\mathrm{e}, \mathrm{x}, \mathrm{my} \text {.sons }>=\sigma_{<e^{\prime}, \mathrm{y}, \mathrm{s}>} \cdot \mathrm{y}<\mathrm{x} \&|\mathrm{y}|=3 \& \mathrm{~s}<\mathrm{my} \text {.sons \& }|\mathrm{s}|=1 \& \\
& \mathrm{e}^{\prime}<\mathrm{e} \& \text { Participant(e',y) \& Participant(e',s) }
\end{aligned}
$$

There is a (plural) event e of my sons catching a group of fish $x$, and and e can be broken down into subevents e' such that three fish from $x$ participate in $e^{\prime}$ and one son participates in $e^{\text {' }}$

To begin, I will assume that sentence (86a) can receive the LF in (90a), where the null pronoun within the binominal each construction is bound by the subject my sons (Heim \& Kratzer 1998). Given this structure, our semantics in (89) yields the truth-conditions in (90b). As noted above, these truth-conditions can be read informally as follows: (i) there is a (plural) event e of my sons catching a group of fish $\mathrm{x}$, and (ii) the event e can be broken down into subevents e' where three fish participate and where one son participates.

Given these truth-conditions, we correctly predict that (86a) will be judged true in a participant distributive scenario like (87a) above. Note that in (87a), the plural event $e_{1}+e_{2}$ will witness the existential truth-conditions in (90b). After all, this is a plural event of catching, with my sons as the (cumulative) agent, and a group of fish $\left(\mathrm{fish}_{1}+\ldots+\mathrm{fish}_{6}\right)$ as the (cumulative) theme. Moreover, $\mathrm{e}_{1}+\mathrm{e}_{2}$ can be divided up into subevents where one son and three fish participate. Thus, our semantics captures the truth of (86a) in participant-distributive scenarios. We also predict the falsity of (86a) in event-distributive scenarios like (87b). Note that in that scenario, there is no subevent containing both three fish and one son, and so the truth-conditions in (90b) will fail to hold.

In addition to capturing the core facts in (86)-(87), our analysis also predicts the related fact in (91a). As has often been noted, binominal each in English differs from distributive numerals in that it requires there to be at least two plural NPs within the sentence (cf. (38)).

\section{(91) Binominal Each Requires Two Plural NPs}

a. Ill-Formed Sentence: * My son caught three fish each.

b. $\quad$ Predicted Truth-Conditions

$$
\begin{aligned}
& \exists \text { e . } \exists \text { x. } * \text { fish }(\mathrm{x}) \& * \operatorname{catch}(\mathrm{e}) \& * \operatorname{Agent}(\mathrm{e})=\text { my.son } \& * \text { Theme }(\mathrm{e})=\mathrm{x} \& \\
& <\mathrm{e}, \mathrm{x}, \mathrm{my} \cdot \operatorname{son}>=\sigma_{<\mathrm{e}, \mathrm{y}, \mathrm{s}>} \cdot \mathrm{y}<\mathrm{x} \&|\mathrm{y}|=3 \& \mathrm{~s}<\mathrm{my} \text {.son } \&|\mathrm{~s}|=1 \& \\
& \text { e' }<\text { e \& Participant(e',y) \& Participant(e',s) }
\end{aligned}
$$

As the reader can confirm, our analysis in (88)-(89) predicts that (91a) will have the truthconditions in (91b). Importantly, the truth-conditions in (91b) are contradictory. Given that the singular subject my son denotes an atom, it follows that there is no s such that $\mathrm{s}<$ my.son $\&|\mathrm{~s}|=$ 1 , and so the truth-conditions in (91b) could never be satisfied. It follows, then, that speakers will perceive sentences like (91a) to be anomalous (Gajewski 2009).

One final difference between binominal each and canonical distributive numerals concerns the possibility of inverse scope readings. While such readings are possible for sentences 
containing distributive numerals (35), (Zimmermann 2002, Oh 2005), binominal each strongly resists inverse scope, as illustrated below.

\section{No Inverse Scope with Binominal Each}

a. Two flagpoles stood in front of every house. (inverse scope possible)

b. $\quad *$ Two flagpoles each stood in front of the houses. (inverse scope impossible)

Interestingly, this fact can be seen to follow from our core syntactic assumption in (88). Given the null pronominal within the binominal each construction, the only way to obtain an inverse scope reading for (92b) would be to QR the phrase the houses above two flagpoles each. However, as shown below, such movement would lead to a Weak Cross Over configuration, and so would violate general, well-known conditions on QR.

\section{Inverse Scope with Binominal Each Leads to Weak Cross Over}

[s $\exists \mathrm{e}$ [s [the houses] [s 1 [ ${ }_{\nu \mathrm{P}}$ [two flagpoles each pro $\left._{1}\right]\left[{ }_{\nu \mathrm{P}} v\left[{ }_{\nu \mathrm{P}}\right.\right.$ stood in front of $\left.\left.t_{1}\right] \ldots\right]$

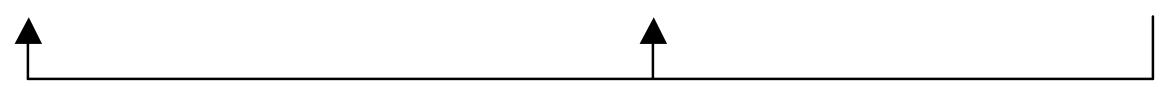

Weak Cross Over Configuration

\section{Conclusion}

The principal empirical focus of this paper has been the distributive suffix -gáa of Tlingit. We have seen that the expressions derived by this suffix are aptly labeled as 'distributive numerals' or 'distance distributives'. Moreover, we have seen that such expressions can, like distributive numerals in other languages, attach either adnominally or adverbially. Furthermore, sentences containing distributive numerals appear at first glance to ambiguous, in that they can describe either participant-distributive or event-distributive scenarios.

While similar facts in other languages have been treated as cases of ambiguity, we have seen that it is possible to provide a univocal semantics for Tlingit -gáa, one that yields truthconditions broad enough to cover both participant- and event-distributive scenarios. This semantics also captures a number of additional features of Tlingit distributive numerals, ones that have been widely observed for distributive numerals in other languages. Importantly, the proposed semantics makes no actual use of distributive operators akin to that in (2), and thereby avoids several key problems that arise for analyses making use of such operators (Oh 2001, 2005; Zimmermann 2002, Champollion 2012). Furthermore, the proposed semantics is based entirely on relatively simple and commonplace assumptions concerning the syntax-semantics interface (Section 5.1), in contrast to prior accounts making use of the DPIL framework (Henderson 2011, Dotlačil 2012). It should therefore be noted that the proposed semantics in turn provides additional, indirect support for those assumptions, which have proven so crucial to our broader understanding of the semantics of plurality (Kratzer 2003, 2008).

It seems, then, that the general approach taken here might also yield viable analyses of distributive numerals across many languages. In support of this, we have seen that our semantics can offer novel answers to puzzles surrounding distributive numerals in Korean, German and Kaqchikel. For Korean and German, our account straightforwardly predicts certain 'locality effects' observed for distributive numerals. In the case of Kaqchikel, the proposed semantics 
provides an elegant explanation for the observed interactions between distributive numerals and pluractional morphology. Finally, we've seen that a slight augmentation of our semantics can capture the distinctive properties of the English binominal each construction, including its intolerance for inverse scope readings.

Of course, much work remains to be done before the semantics developed here could be viewed as a general theory of distance distributivity. One difficult puzzle for future research concerns a phenomenon that might be labeled 'distributive concord'. As documented by Oh (2005), it is possible for distributive numerals in Korean to appear within the scope of the distributive marker kakkak 'each'. As illustrated below, in such sentences, the presence of the distributive suffix -ssik is felt to contribute nothing to the overall truth-conditions, but in some sense simply 'reinforces' the distributivity contributed by kakkak'each'.

$$
\begin{array}{llllll}
\multicolumn{2}{l}{\text { Korean Kakkak'Each' Licenses the Appearance of Distributive Ssik (Oh 2005) }} \\
\begin{array}{llllll}
\text { Haksayng } & \text { twu-myeng-i } & \text { kakkak sangca } & \text { han-kay-(ssik)-lul wunpanhayssta. } \\
\text { student } & \text { two-CL-NOM } & \text { each } & \text { box } & \text { one-CL-DIST-ACC } & \text { carried }
\end{array}
\end{array}
$$

'Two students each carried one box.'

A similar phenomenon can be observed in English, as noted by Brasoveanu \& Henderson (2009), Szabolcsi (2011), and Dotlačil (2012). Note that in sentences like the following, the distributive determiner each is somewhat redundant, and seems only to reinforce the distributive contribution of one by one.

\section{Interaction Between One by One and Each in English}

One by one, each student read a poem.

Like most other theories of distance distributivity (Zimmermann 20002, Champollion 2012, Dotlačil 2012; but $c f$. Oh 2001, 2005; Brasoveanu \& Henderson (2009)), the semantics developed here cannot directly account for the reported meanings of (94) and (95). However, the failure here needn't necessarily lie in the proposed semantics for distance distributives, but could instead indicate that a more sophisticated semantics is needed for the distributive markers kakkak and each. At any rate, the exact consequences that such 'distributive concord' holds for the account proposed here constitute an important problem for future research along these lines.

\section{References}

Balusu, Rajul. 2006. "Distributive Reduplication in Telugu." In Davis, Christopher, Amy Rose Deal and Youri Zabbal (eds) Proceedings of the $36^{\text {th }}$ Annual Meeting of the North East Linguistic Society. Amherst, MA: GLSA.

Barker, M.A.R. 1964. Klamath Grammar: University of California Publications in Linguistics 38. Berkeley: University of California Press.

Beck, Sigrid. 2006. "Intervention Effects Follow from Focus Interpretation." Natural Language Semantics. 14: 1-56.

Beck, Sigrid and Shin-Sook Kim. 1997. "On Wh- and Operator Scope in Korean." Journal of East Asian Linguistics 6: 339-384.

Beck, Sigrid and Arnim von Stechow. 2007. "Pluractional Adverbials." Journal of Semantics 24: 215-254. 
van den Berg, Martin. 1996. Some Aspects of the Internal Structure of Discourse. PhD Dissertation. University of Amsterdam.

Boas, Franz. 1917. "Grammatical notes on the Language of the Tlingit Indians." University of Pennsylvania University Museum Anthropological Publications 8:1.

Brasoveanu, Adrian. 2008. "Donkey Pluralities: Plural Information States versus Non-Atomic Individuals." Linguistics and Philosophy 31: 129-209.

Brasoveanu, Adrian and Robert Henderson. 2009. "Varieties of Distributivity: One by One vs. Each." In Cormany, Ed, Satoshi Ito, and David Lutz (eds) Proceedings of SALT XIX. Ithaca NY: CLC Publications.

Cable, Seth. 2010. The Grammar of Q: Q-Particles, Wh-Movement, and Pied-Piping. Oxford: Oxford University Press.

Campbell, Lyle. 1997. American Indian Languages: The Historical Linguistics of Native America. Oxford: Oxford University Press.

Champollion, Lucas. 2012. "Each vs. Jeweils: A Cover-Based View on Distance Distributivity." In Aloni, Maria, Vadim Kimmelman, Floris Roelofsen, Galit W. Sassoon, Katrin Schulz, and Matthijs Westera (eds) Logic, Language, and Meaning: $18^{\text {th }}$ Amsterdam Colloquium; Amsterdam, The Netherlands, December 19-21 2011: Revised Selected Papers. Berlin: Spring-Verlag.

Choe, Jae-Woong. 1987. Anti-Quantifiers and a Theory of Distributivity. PhD Dissertation. University of Massachusetts Amherst.

Cusic, David. 1981. Verbal Plurality and Aspect. PhD Dissertation. Stanford University.

Dauenhauer, Nora Marks and Richard Dauenhauer. 1987. Classics of Tlingit Oral Literature, Volume 1: Haa Shuká, Our Ancestors: Tlingit Oral Narratives. Juneau, AK: Sealaska Heritage Institute.

Dauenhauer, Nora Marks and Richard Dauenhauer. 2000. Beginning Tlingit. Juneau, AK: Sealaska Heritage Institute.

Dotlačil, Jakub. 2012. "Binominal Each as an Anaphoric Determiner: Compositional Analysis." In Aguilar, Ana, Anna Chernilovskaya, and Rick Nouwen (eds) Sinn und Bedeutung 16. Cambridge, MA: MIT Working Papers in Linguistics.

Edwards, Keri. 2009. Dictionary of Tlingit. Juneau, AK: Sealaska Heritage Institute.

Farkas, Donka. 1997. "Dependent Indefinites." In Corblin, F., and D. Godard, and J.-M. Marandin (eds), Empirical Issues in Formal Syntax and Semantics Peter Lang Publishers.

Gajewski, Jon. 2009. "L-Triviality and Grammar." Manuscript. University of Connecticut. Accessed online 6/22/2012 at: http://gajewski.uconn.edu/papers/Logic.pdf

van Geenhoven, Veerle. 2004. "For-Adverbials, Frequentative Aspect, and Pluractionality." Natural Language Semantics 12: 135-190.

Gil, David. 1982. Distributive Numerals. PhD Dissertation. UCLA.

Heim, Irene and Angelika Kratzer. 1998. Semantics in Generative Grammar. Oxford: Blackwell.

Henderson, Robert. 2011. "Pluractional Distributivity and Dependence." In Ashton, Neil, Anca Chereches, and David Lutz (eds) Proceedings of SALT XXI. Ithaca NY: CLC Publications.

Kratzer, Angelika. 1996. "Severing the External Argument from its Verb." In Rooryck, Johan and Laurie Zaring (eds) Phrase Structure and the Lexicon. Dordrecht: Kluwer.

Kratzer, Angelika. 2003. The Event Argument. Manuscript. University of Massachusetts Amherst. Accessed 6/22/2012: http://www.semanticsarchive.net/Archive/GU1NWM4Z/

Kratzer, Angelika. 2008. "On the Plurality of Verbs." In Doelling, Johannes, Tatjana Heyde 
Zybatow, and Martin Schaefer (eds), Event Structures in Linguistic Form and Interpretation. New York: Mouton de Gruyter.

Krifka, Manfred. 1990. "Four Thousand Ships Passed Through the Lock: Object-Induced Measure Functions on Events." Linguistics and Philosophy 13: 487-520.

Krifka, Manfred. 1992. "Thematic Relations as Links Between Nominal Reference and Temporal Constitution." In Sag, Ivan and Anna Szabolcsi (eds) Lexical Matters. Stanford, CA: CSLI.

Landman, Fred. 2000. Events and Plurality: The Jerusalem Lectures. Dordrecht: Kluwer.

Lasersohn, Peter. 1995. Plurality, Conjunction, and Events. Dordrecht: Kluwer.

Lasersohn, Peter. 2011. "Mass Nouns and Plurals." In von Heusinger, Klaus, Claudia Maienborn, and Paul Porner, (eds) Semantics: An International Handbook of Natural Language Meaning. Berlin: Mouton de Gruyter.

Leer, Jeff. 1991. The Schetic Categories of the Tlingit Verb. PhD Dissertation. University of Chicago.

Leer, Jeff. 2010. "The Palatal Series in Athabaskan-Eyak-Tlingit, with an Overview of the Basic Sound Correspondences." In Kari, James and Ben A. Potter (eds) The Dene-Yeniseian Connection: Anthropological Papers of the University of Alaska, Volume 5 (1-2). Fairbanks, AK: Alaska Native Language Center.

Leer, Jeff, Doug Hitch and John Ritter. 2001. Interior Tlingit Noun Dictionary: The Dialects Spoken by Tlingit Elders of Carcross and Teslin, Yukon, and Atlin, British Columbia. Whitehorse: Yukon Native Language Centre.

Link, Godehard. 1983. "The Logical Analysis of Plurals and Mass Terms: a Lattice-Theoretical Approach.” In Bäuerle, Rainer, Cristoph Schwarze, and Arnim von Stechow (eds) Meaning, Use and Interpretation of Language. Berlin: de Gruyter.

Matthewson, Lisa. 2004. "On the Methodology of Semantic Fieldwork." International Journal of American Linguistics 70: 369-415.

May, Robert. 1985. Logical Form: its Structure and Derivation. Cambridge, MA: MIT Press.

May, Robert. 1988. "Ambiguities of Quantification and Wh: a Reply to Williams." Linguistic Inquiry 19: 118-135.

Mithun, Mariane. 1999. The Languages of Native North America. Cambridge: Cambridge University Press.

Naish, Constance. 1966. A Syntactic Study of Tlingit. Language Data: Amerindian Series 6. Dallas, TX: SIL International.

Newman, Paul. 1990. Nominal and Verbal Plurality in Chadic. Dordrecht: Foris.

Oh, Sei-Rang. 2001. "Distributivity in an Event Semantics." In Hastings, R., B. Jackson, and Z. Zvolensky (eds) Proceedings of SALT XI. Ithaca, NY: CLC Publications.

Oh, Sei-Rang. 2005. Plurality Markers Across Languages. PhD Dissertation. University of Connecticut.

Safir, Ken and Tim Stowell. 1988. "Binominal Each." In Blevins, Juliet and J. Carter (eds) NELS 18: Proceedings of the 18 ${ }^{\text {th }}$ Annual Meeting of the North East Linguistic Society. Somerville, MA: Cascadilla Press.

Scha, Remko. 1984. "Distributive, Collective, and Cumulative Quantification." In Groenendijk, Jeroen, Theo Janssen, and Martin Stokhof (eds), Truth, Interpretation, and Information. Dordrecht: Foris.

Schwarzschild, Roger. 1996. Pluralities. Dordrecht: Kluwer. 
Story, Gillian. 1966. A Morphological Study of Tlingit. Language Data: Amerindian Series 7. Dallas, TX: SIL International.

Szabolcsi, Anna. 2011. Quantification. Cambridge: Cambridge University Press.

Winter, Yoad. 2000. "Distributivity and Dependency." Natural Language Semantics 8: 27-69.

Zimmermann, Malte. 2002. Boys Buying Two Sausages Each: On the Syntax and Semantics of Distance-Distributivity. PhD Dissertation. University of Amsterdam. 